\title{
Characteristics of the Perception of Different Severity Measures of Citrus Canker and the Relationships Between the Various Symptom Types
}

\author{
C. H. Bock, University of Florida/USDA, 2001 S. Rock Rd., Ft. Pierce, FL 34945; P. E. Parker and A. Z. Cook, \\ USDA-APHIS, Moore Air Base, Edinburg, TX 78539; and T. R. Gottwald, USDA-ARS-USHRL, 2001 S. Rock Rd., \\ Ft. Pierce, FL 34945
}

\begin{abstract}
Bock, C. H., Parker, P. E., Cook, A. Z., and Gottwald, T. R. 2008. Characteristics of the perception of different severity measures of citrus canker and the relationships between the various symptom types. Plant Dis. 92:927-939.

Citrus canker is a disease of citrus and is caused by the bacterial pathogen Xanthomonas citri subsp. citri. Ways of managing the disease are being sought, and accurate, precise, reproducible disease assessment is needed for monitoring epidemics. The objective of this study was to investigate the characteristics of visual assessment of citrus canker symptoms compared with actual disease measured using image analysis (IA). Images of 210 citrus leaves with a range of incidence and severity of citrus canker were assessed by three plant pathologists (VR1-3) and by IA. The number of lesions (L), \% area necrotic $(\% \mathrm{AN})$, and \% area necrotic+chlorotic (\%ANC) were assessed. The best relationships were found between $\% \mathrm{AN}$ and $\% \mathrm{ANC}\left(r^{2}=0.41\right.$ to 0.87$)$, and the worst between $\mathrm{L}$ and \% AN ( $r^{2}=0.27$ to 0.66$)$. Bland-Altman plots showed various sources of rater error in assessments, including under- and over-estimation, proportional error, and heterogeneity of variation dependent on actual disease magnitude. There was a tendency to overestimate area diseased, but not lesion counts, and this tendency was pronounced at lower disease severity, with a leaf having more lesions tending to be assessed as having greater area infected compared with a leaf with fewer lesions but equal actual area infected. The rater estimations of disease were less accurate or precise with increasing actual disease severity as indicated by the fit of a normal probability density function-the incidence of extreme values increases with increasing actual disease. For example, for \%ANC the kurtosis of the distribution ranged from 17.92 to $1.18,0.51$, and 0.22 in actual disease category ranges of 0 to 10,11 to 20,21 to 30 , and 31 to $40 \%$ area infected, respectively. The log variance of the estimates plotted against $\log$ actual disease for all three raters over two assessment occasions gave a linear relationship for L, \%AN, and \%ANC ( $r^{2}=0.74,0.65$, and 0.74 , respectively). Training should improve the accuracy, precision, and reproducibility of raters, and knowledge of the characteristics of disease assessment should help develop and target the training more appropriately and address specific causes and sources of error.
\end{abstract}

Citrus canker, a disease of several citrus species and cultivars, is caused by the bacterial pathogen Xanthomonas citri subsp. citri. The disease is important in wet tropical and subtropical citrusgrowing regions, as infection results in yield loss and severely blemished fruit unsuitable for the fresh market $(12,32)$. Ways of managing the disease are being studied and sought, and accurate, precise, and reproducible disease assessment is a component of many of these studies and is needed for monitoring the canker epidemic (32). Indeed, the accurate and precise estimate of plant disease is important not only for monitoring epidemics but also for estimating yield

Corresponding author: C. H. Bock

E-mail: cbock@ushrl.ars.usda.gov

Accepted for publication 8 February 2008.

doi:10.1094/PDIS-92-6-0927

(C) 2008 The American Phytopathological Society loss and breeding for resistance against plant diseases $(11,22,24,26,33)$.

Symptoms of citrus canker that may need to be assessed include numbers of lesions and lesion area. Lesion area includes both necrotic areas and associated chlorosis. How the symptom components relate to one another has not been investigated. The possibility that symptom characteristics (for example, lesion count) may influence the accuracy and precision of rating citrus canker has not been investigated but can provide useful information when considering training raters, as well as choosing the most relevant symptoms to assess for a particular purpose.

Some characteristics of canker assessment have been studied in relation to visual assessment and image analysis (4,7), and some general characteristics of foliar disease symptom assessment apply $(24,26)$. A standard disease assessment diagram set, in part based on the WeberFechner law, was recently developed for citrus canker, and was shown to aid in disease assessment (4). However, the Weber-Fechner law (on which the Horsfall-
Barratt [H-B] disease assessment scale [16] is based) does not exist $(3,26,29,34)$. The Weber-Fechner law in fact comprises two separate laws, Weber's law and Fechner's law $(3,26,29,34)$. Weber's law states that the difference threshold (the point at which a stimulus is perceived as different) is a constant fraction of the stimulus intensity. Fechner accepted Weber's law but theorized that acuity depended on the logarithm of the intensity of the stimulus, and the resulting relationship became known as the Weber-Fechner law $(3,16-18,34)$. Thus, the rationale for the logarithmic nature of the H-B scale is perceived to mean that actual disease severity must double for a rater to perceive a difference in disease severity. This could extend to a systematic relationship between the variance of the estimate and actual severity: the ability to accurately and precisely estimate disease at low disease severity may be much better than at near $50 \%$ disease (10,16-18,29,31). Since Horsfall and Barratt first described their scale, various reports have defined the relationship between estimated and actual disease $(15,24,26,28,29,33)$, and that between the variance, or error, of the estimate and actual disease $(9,10,13,19,24,29)$. Understanding both the overall relationship between estimated and actual disease and the relationship between magnitude of the variance of the estimate and actual disease are important for improving plant disease assessment.

Reports in the literature demonstrate a basically linear relationship between estimated and actual disease for many diseases $(24,26,29,33)$, and this appears to be the case with citrus canker symptoms as well $(4,7)$. Nutter and Esker (26), using psychophysical methods (threshold estimation based on the just noticeable difference, or jnd), showed that disease levels of 25, 37, and $50 \%$ were assessed with similar error, suggesting a further category could be incorporated in the H-B scale, and also suggesting that there was not a logarithmic relationship between 25 and 50\%. Forbes and Jeger (9) had previously found that the $\mathrm{H}-\mathrm{B}$ assumptions regarding variance did not hold between 25 and $75 \%$ disease, but variance was less at lower severity $(<25 \%)$ and in general agreement with the assumptions of Horsfall and Barratt. However, the magnitude of the actual severity per se was found not to be a source of error in at least one study (24), although components of 
the pathosystem (lesion number and leaflet size) did contribute to the error with increasing severity. The variance associated with direct estimates has yet to be unequivocally characterized over the full range from 0 to $100 \%$ disease. Raters do appear more comfortable rating disease severity $<25 \%$ compared with severity $>25 \%$, where they opt for "knot" values $(7,13,19)$. Indeed, it is especially important to understand the characteristics of disease assessment below $35 \%$, as the majority of leaf spotting diseases, including citrus canker $(4,7)$, generally exist at severities $<35 \%(21,33)$.
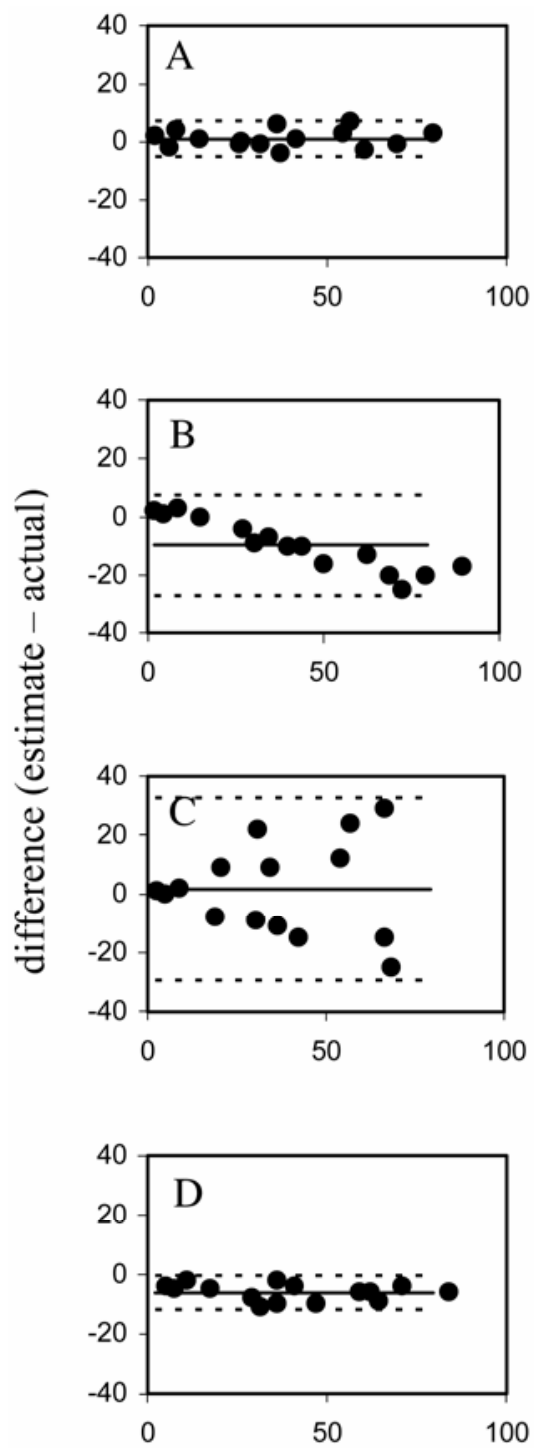

Actual value

Fig. 1. Bland-Altman plots showing some characteristic relationships regarding reproducibility between, or repeatability of, methods. Solid line represents the mean of the two methods or the repeat measures, upper and lower dashed lines indicate $95 \%$ levels of agreement (mean $+/-$ $1.96 \sigma)$. A, acceptable repeatability or reproducibility, $\mathbf{B}$, proportional error, $\mathbf{C}$, variation of at least one method is highly dependent on the magnitude of the measurement, D, consistent under/over estimate by at least one method.
Other factors may confound the reproducibility of disease assessment. There may be an inherent tendency to overestimate $\%$ area over some severities $(1,14$, 20,33). The number and size of lesions can affect the estimate: many small lesions at a given severity tend to result in greater error $(1,24,33)$, further complicating perception of severity. The interplay of these factors is not fully understood but may help in training raters and improving the quality of assessments in the future $(4,23,26,27$, 29,30).

The objectives of this study included the following: (i) investigate relationships among foliar symptom types of citrus canker; (ii) assess the effects of lesion number and area on estimates of severity; (iii) characterize the effect of actual disease magnitude on assessed estimates of disease and any tendencies to over- or under-estimate; and (iv) assess the variance of unaided direct visual estimates with increasing magnitude of actual severity.

\section{MATERIALS AND METHODS}

Assessment of images. All leaves were obtained from naturally infected plants reflecting a range of disease occurring in the field. Leaf and lesion age varied. A total of 210 leaves were photographed, and the images were printed ( 6 per page) to provide images close to the actual size of the leaf. The images were assessed by three plant pathologists (VR1-3) and by image analysis (IA) using the Assess Image Analysis Software (APS Press, St. Paul, MN). The assessments were made twice. The details of these processes have already been described (7). Image analysis provides a way of assessing disease that can remove considerable bias and error, and performs lesion counts and measures the $\%$ area infected. For these reasons, it was used as the "actual" value for citrus canker severity to compare with the visual assessments (7). IA can suffer from inability to differentiate complex symptoms such as coalesced lesions, which a rater could readily discern, so each image was groundtruthed to ensure the leaf was accurately and precisely measured by IA. Automation of disease assessment is a goal, but IA currently operates with a set of static instructions, although forms of artificial intelligence may eventually permit more dynamic rating.

Data analysis. All data were analyzed using SAS (SAS Institute, Cary, NC). Regression analysis (PROC REG) was used to investigate the relationship between different symptom types for image analysis and for each rater to investigate the relationship among the different measures of disease (\% area necrotic, $\%$ area necrotic+chlorotic, and lesion counts). Good relationships $\left(r^{2}>95 \%\right.$, intercept $=0$, slope $=1$ ) between different measures of disease would suggest that they might be interchangeable for disease assessment, while a poorer relationship would indicate the need to assess a specific symptom type (lesion count or a component of area infected) for certain purposes.

The frequency of over- and under-estimates was calculated for each rater, assessment, and symptom type, and the percent difference between actual and visual estimate was calculated for each data point. Lesion count and size is known to influence estimates of area infected $(1,33)$. Regression analysis (PROC REG) was used to investigate the relationship between actual and perceived citrus canker to assess the effect of lesion counts and area for both estimates of $\%$ area necrotic and $\%$ area necrotic+chlorotic. The ratio of visual rater estimate:actual diseased area was also regressed against actual disease to discern if there was a relationship with the magnitudes of disease severity assessment (33). Various single-factor $(y=a+b x)$ and two-factor $(y=a+b x+c x)$ models were tested to investigate whether area and/or lesion count influenced the relationship by incorporating different combinations of the independent variables lesion count $(L)$, $\log _{\mathrm{e}} L, \sqrt{ } L, \%$ area necrotic (\%Nec), $\log _{\mathrm{e}} \% \mathrm{Nec}, \sqrt{ } \% \mathrm{Nec}, \%$ area necrotic+ chlorotic $(\% \mathrm{Nec}+\mathrm{Chl}), \quad \log _{\mathrm{e}} \% \mathrm{Nec}+\mathrm{Chl}$, $\sqrt{ } \% \mathrm{Nec}+\mathrm{Chl}$. Coefficient of determination $\left(r^{2}\right)$, the coefficient of variation $(C V)$, and slope and intercept parameters were estimated for each regression solution to test for goodness of fit. The data were analyzed using general linear modeling (PROC GLM) to assess the effects of the different disease parameters (lesion counts and diseased area). Zero values were not included in this analysis.

Bland-Altman plots (Fig. 1) were used to assess the characteristics of the reproducibility and bias within and between rating methods and raters for each symptom type $(5,6)$ and provide additional insights into inter- and intra-rater repeatability, and inter-method reproducibility compared with other methods $(7,24,29)$. They are widely used in clinical assays to assess reproducibility of medical and pharmaceutical tests $(6,8)$. The plots show the difference (estimated - actual) against the mean value, and the patterns of these data points show how methods compare or how close repeat estimates are, and if they differ, the characteristics of those differences (including detection of over- and underestimation, systematic and proportional error (heterogeneity of variance). Repeatability by each method was tested with the coefficient of repeatability $(C R)$ where:

$C R=1.96 \sqrt{\frac{\sum\left(d_{2}-d_{1}\right)^{2}}{n-1}}$

and $d_{2}$ and $d_{1}$ are the sample data for assessment 1 and 2, respectively, and $n$ is the number of leaves assessed. Reproducibility between, and repeatability within, image analysis and visual raters was also tested 
based on the $95 \%$ limits of agreement (6), by taking the mean difference $d$ and the standard deviation of the difference $\sigma_{d}$, such that the $95 \%$ agreement limit is equal to $d+/-1.96 * \sigma_{d}$.

For each symptom type, the discrepancy of each visual estimate from its actual value was calculated. Each rater estimate (VR1-3) was subtracted from the actual value (IA assessment) for that particular leaf for each assessment 1 and 2. This gave a discrepancy range across raters and disease severities for each disease estimate. These values were grouped into categories based on IA values of 0 to 10,11 to 20,21 to 30 , and 31 to 40 for lesion count and $\%$ area necrotic+chlorotic, and into groups of 0 to 3,4 to 6,6 to 9,9 to 12 , and 13 to 15 for $\%$ area necrotic so that each category contained the rater discrepancy values for the actual severities in that range. Each resulting category of + and - values was charted to gauge the frequency and distribution range of the estimate discrepancies. SAS PROC UNIVARIATE was used to fit a normal probability density function for each category range of discrepancies:

$$
p(x)=\frac{1}{\sigma(\sqrt{2 \pi})} e^{\frac{-(x-\mu)^{2}}{2 s^{2}}}
$$

where $\mu$ is the mean, $\sigma$ is the standard deviation and $s^{2}$ the sample variance, $x$ the values for the $X$ axis, and $e$ the exponent. In addition to $\mu$ and $\sigma$ for each fit of the normal probability, various statistics were estimated to assess how well the data were fit by the normal distribution. Tests of the location of the mean were performed to see if it fell within that expected (Student's $t$ test), and estimates of the kurtosis and skewness were made. Kurtosis is a mea- sure of how amplitude of the peak compares with the tails of the probability distribution; positive, higher values denoting more frequent occurrence of extreme values. Skewness of the slope is a measure of the asymmetry of the probability distribution. Two tests were done to see whether the distribution was significantly different from the normal (the Kolmogorov-Smirnov [K-S] and AndersonDarling [A-D] tests). The latter is a modification of the K-S test but gives more weight to the tails, and whereas the K-S test is distribution free, the A-D test uses the specific distribution in calculating critical values, which makes for a more sensitive test.

White's test for heteroscedasticity was performed on the data to establish whether nonhomogeneity of variance occurred with increasing disease severity. The White

Table 1. Regression analysis ${ }^{\mathrm{a}}$ and parameters for the relationship between lesion count and $\%$ area necrotic+chlorotic, lesion count and $\%$ area necrotic, and $\%$ area necrotic+chlorotic and \% area necrotic for severity of citrus canker symptoms on grapefruit leaves assessed by image analysis and each of three visual raters on two occasions

\begin{tabular}{|c|c|c|c|c|c|c|c|c|}
\hline Relationship & Assessment & Rater & $r^{b}$ & $a^{\mathrm{c}}$ & $b^{\mathbf{d}}$ & $C V^{\mathrm{e}}$ & $S E^{\mathbf{f}}$ & $r^{2 g}$ \\
\hline \multirow{8}{*}{$\begin{array}{l}\text { Lesion count vs. } \\
\% \text { area necrotic+chlorotic }\end{array}$} & \multirow[t]{4}{*}{1} & IA & $0.68 * * *$ & $3.75 * * *$ & $0.30 * * *$ & 80.6 & 7.30 & 0.47 \\
\hline & & VR1 & $0.78 * * *$ & $2.95 * * *$ & $0.43 * * *$ & 72.0 & 8.04 & 0.65 \\
\hline & & VR2 & $0.81 * * *$ & $4.23 * * *$ & $0.25 * * *$ & 64.6 & 4.89 & 0.55 \\
\hline & & VR3 & $0.79 * * *$ & $2.78 * * *$ & $0.49 * * *$ & 67.8 & 7.22 & 0.63 \\
\hline & \multirow[t]{4}{*}{2} & IA & $0.64 * * *$ & $3.94 * * *$ & $0.27 * * *$ & 84.1 & 7.44 & 0.42 \\
\hline & & VR1 & $0.65 * * *$ & $4.77 * * *$ & $0.22 * * *$ & 83.2 & 7.38 & 0.43 \\
\hline & & VR2 & $0.75 * * *$ & $2.29 * * *$ & $0.29 * * *$ & 84.3 & 6.31 & 0.56 \\
\hline & & VR3 & $0.73 * * *$ & $5.70 * * *$ & $0.29 * * *$ & 72.4 & 8.95 & 0.53 \\
\hline \multirow{8}{*}{$\begin{array}{l}\text { Lesion count vs. } \\
\% \text { area necrotic }\end{array}$} & \multirow[t]{4}{*}{1} & IA & $0.59 * * *$ & $1.71 * * *$ & $0.09 * * *$ & 84.8 & 2.81 & 0.35 \\
\hline & & VR1 & $0.52 * * *$ & $2.26 * * *$ & $0.07 * * *$ & 77.1 & 2.66 & 0.27 \\
\hline & & VR2 & $0.70 * * *$ & $2.76^{* * * *}$ & $0.14 * * *$ & 66.5 & 3.45 & 0.49 \\
\hline & & VR3 & $0.81 * * *$ & $1.83 * * *$ & $0.21 * * *$ & 57.1 & 2.98 & 0.66 \\
\hline & \multirow[t]{4}{*}{2} & IA & $0.57 * * *$ & $1.83^{* * *} *$ & $0.09 * * *$ & 87.6 & 3.00 & 0.32 \\
\hline & & VR1 & $0.57 * * *$ & $3.07 * * *$ & $0.06 * * *$ & 57.4 & 2.34 & 0.32 \\
\hline & & VR2 & $0.83 * * *$ & $1 . .69 * * *$ & $0.17 * * *$ & 60.0 & 2.83 & 0.69 \\
\hline & & VR3 & $0.64 * * *$ & $2.79 * * *$ & $0.08 * * *$ & 66.4 & 3.02 & 0.41 \\
\hline \multirow{8}{*}{$\begin{array}{l}\% \text { area necrotic }+ \text { chlorotic vs. } \\
\% \text { area necrotic }\end{array}$} & \multirow[t]{4}{*}{1} & IA & $0.90 * * *$ & 0.55 & $2.57 * * *$ & 48.8 & 4.34 & 0.80 \\
\hline & & VR1 & $0.66 * * *$ & 1.29 & $2.71 * * *$ & 91.5 & 9.65 & 0.41 \\
\hline & & VR2 & $0.88 * * *$ & $0.84 *$ & $1.51 * * *$ & 46.2 & 3.96 & 0.77 \\
\hline & & VR3 & $0.93 * * *$ & -0.77 & $2.16 * * *$ & 40.4 & 4.33 & 0.87 \\
\hline & \multirow[t]{4}{*}{2} & IA & $0.91 * * *$ & 0.50 & $2.42 * * *$ & 45.4 & 4.01 & 0.83 \\
\hline & & VR1 & $0.77 * * *$ & $-1.87 *$ & $2.61 * * *$ & 70.7 & 6.20 & 0.59 \\
\hline & & VR2 & $0.93 * * *$ & $-0.78 *$ & $1.74 * * *$ & 47.7 & 3.51 & 0.86 \\
\hline & & VR3 & $0.85^{* * * *}$ & -0.46 & $2.80 * * *$ & 55.6 & 6.90 & 0.72 \\
\hline
\end{tabular}

\footnotetext{
a Regression model $y=a+b x$.

b $r=$ Pearson's correlation coefficient; $* * *=P<0.001$.

c $a=$ intercept; $* * *=P<0.001, *=P<0.05$.

d $b=$ slope; $* * *=P<0.001$.

e $C V=$ coefficient of variability.

f $S E=$ standard error of the prediction.

g $r^{2}=$ coefficient of determination.
}

Table 2. Proportions (\%) of over- and under-estimates of lesion counts, \% area necrotic, and \% area necrotic+chlorotic by visual raters compared with the actual value from image analysis when estimating the severity of citrus canker symptoms on 210 leaves of grapefruit on two different occasions

\begin{tabular}{|c|c|c|c|c|c|c|c|c|}
\hline \multirow[b]{2}{*}{ Variable } & \multirow[b]{2}{*}{$(\%)$} & \multicolumn{3}{|c|}{ Assessment 1} & \multicolumn{3}{|c|}{ Assessment 2} & \multirow{2}{*}{$\begin{array}{c}\text { Average } \\
(\%)\end{array}$} \\
\hline & & VR1 & VR2 & VR3 & VR1 & VR2 & VR3 & \\
\hline \multirow[t]{3}{*}{ Count of lesions } & Same & 31.4 & 29.5 & 21.9 & 26.2 & 24.8 & 23.3 & 26 \\
\hline & Underestimate & 35.7 & 37.6 & 41.0 & 38.1 & 42.4 & 26.2 & 37 \\
\hline & Overestimate & 32.9 & 32.9 & 37.1 & 35.7 & 32.9 & 50.5 & 37 \\
\hline \multirow[t]{3}{*}{$\%$ area necrotic } & Same & 7.1 & 7.6 & 4.8 & 5.2 & 7.1 & 5.2 & 6 \\
\hline & Underestimate & 35.7 & 14.8 & 16.2 & 16.2 & 23.3 & 20.0 & 21 \\
\hline & Overestimate & 57.1 & 77.6 & 79.0 & 78.6 & 69.5 & 74.8 & 73 \\
\hline \multirow[t]{3}{*}{$\%$ area necrotic+chlorotic } & Same & 6.7 & 7.6 & 4.8 & 5.7 & 6.7 & 5.7 & 6 \\
\hline & Underestimate & 35.2 & 40.0 & 31.9 & 37.6 & 53.8 & 24.3 & 37 \\
\hline & Overestimate & 58.1 & 52.4 & 63.3 & 56.7 & 39.5 & 70.0 & 57 \\
\hline
\end{tabular}




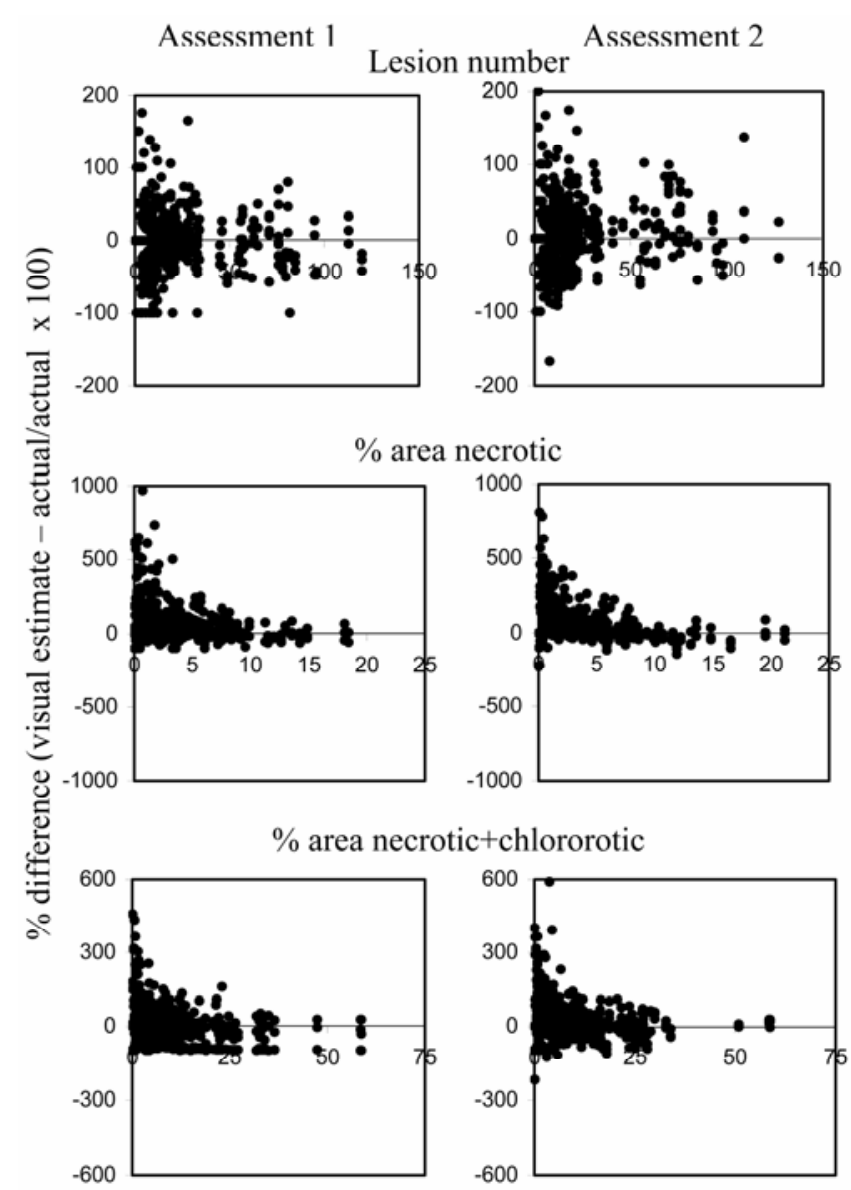

Fig. 2. Relationship between actual disease and percent discrepancy (\% difference) disease for estimates of lesion counts, \% area necrotic, and \% area necrotic+chlorotic by three visual raters assessing the severity of citrus canker symptoms on 210 leaves on grapefruit on two different occasions.

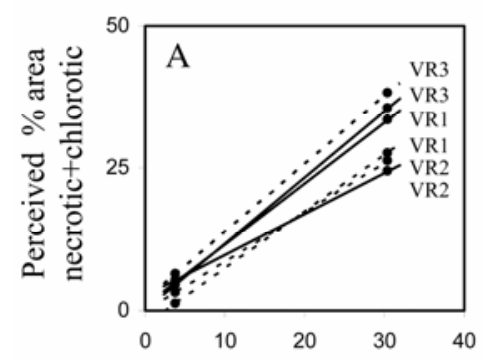

Actual \% area necrotic + chlorotic

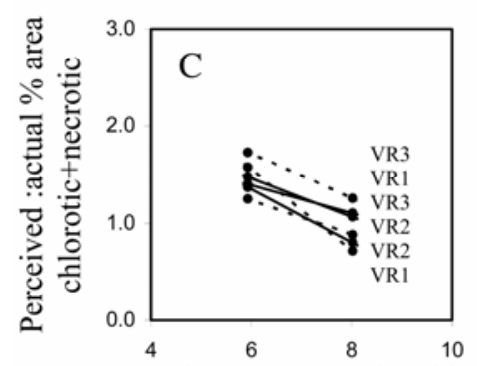

Log actual \% area necrotic + chlorotic

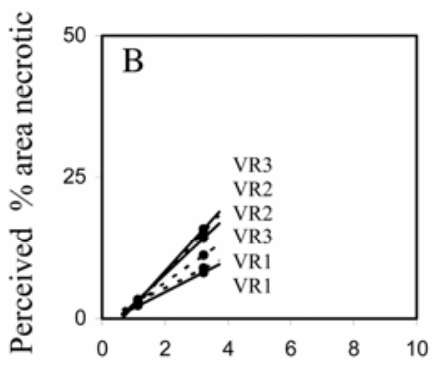

Sq $r t$ actual \% area necrotic

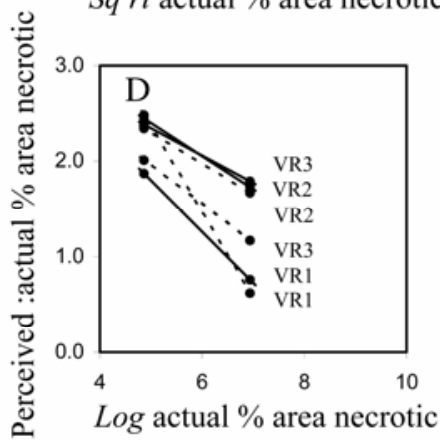

Fig. 3. Regression analysis of the actual disease magnitude plotted against perceived disease magnitude for (A) \% area necrotic+chlorotic, and (B) \% area necrotic, and for the relationship between the ratio perceived $\%$ area disease:actual $\%$ area disease against actual area diseased for (C) $\%$ area necrotic+chlorotic, and (D) \% area necrotic for three raters (VR1-VR3) on assessment 1 (solid lines) and assessment 2 (broken lines). Actual \% area diseased against actual lesion count with intercept of zero, for $\%$ area necrotic+chlorotic, $y=0.38 x$, and for $\%$ area necrotic, $y=0.13 x$. Parameters of regression solutions and models are given in Tables 5 and 6 and were drawn with the assumption from the actual disease regression solutions that the number of lesion/area for 10 lesions $=3.8 \%$, and 80 lesions $=30.4 \%$ area infected for $\%$ area chlorotic+necrotic and 10 lesions $=1.3 \%$ and 80 lesions $=$ $10.4 \%$ area infected for $\%$ area necrotic. Zero values were not included in these models. statistic follows a chi-squared distribution with degrees of freedom equal to the number of independent variables. The test was done for the combined VR estimates from assessment 1 and 2 against the mean actual disease from the two IA assessments for lesion count, $\%$ area necrotic+chlorotic, and $\%$ area necrotic. The variance of estimates from VR1-3 in assessment 1 and 2 were also calculated for each actual value of disease. These data were subject to linear regression analysis (PROC REG) subsequent to $\log -\log$ transformation due to heteroscedasticity.

\section{RESULTS}

Relationships between symptom types. Lesion count was weakly related to the \% area necrotic+chlorotic $\left(r^{2}=0.47\right.$ to 0.65 , Table 1$)$ and to $\%$ area necrotic $\left(r^{2}=0.27\right.$ to 0.66). A slightly better relationship was found between the \% area necrotic and \% area necrotic+chlorotic $\left(r^{2}=0.41\right.$ to 0.87$)$. Correlation coefficients followed a similar trend $(0.64$ to 0.81 and 0.52 to 0.83 , and 0.66 to 0.93 , respectively), and $C V$ s (40.4 to $91.5)$ indicated substantial variation in estimation between symptom types.

Tendency to overestimate and the influence of lesion count and area on perception of area infected. The proportion of overestimates of disease was most prevalent for $\%$ area necrotic and $\%$ area necrotic+chlorotic, and only noticeable with lesion count by rater VR3 during assessment 2 (Table 2). The tendency to overestimate was also most prevalent at lower disease severities (Fig. 2). Regression analysis of different models showed that a single factor best described the relationship between actual \% area chlorotic+ necrotic and the perceived area \% chlorotic+necrotic $\left(r^{2}=0.75\right.$ to 0.83 , Fig. $3 \mathrm{~A})$. Including the factor of lesion count in the model did not improve the overall fit. The slope was significantly different from 1 and the intercept was significantly different from 0 , and dependent on rater and assessment number (Table 3 ). These results were in agreement with the GLM analysis. However, for estimates of the \% area necrotic, a two-factor model was best, incorporating lesion count which played a significant role in influencing the estimate $\left(r^{2}=0.60\right.$ to 0.73 , Fig. 3B). Greater counts of small lesions resulted in overestimates of the $\%$ area necrotic. Some raters (VR1) did not appear to be influenced by number of lesions. The slope and intercepts showed raters varied in the effects of lesion count, which was confirmed in the GLM analysis (Table 3) that showed significant effects due to lesion count, area necrotic and assessment, and interactions between assessment * actual area infected, rater * lesion count, and lesion count * actual area infected.

Comparing the ratio of the VR:IA against IA (actual area occupied by lesions, Fig. 3C and D, and Table 4), signifi- 
cant effects of lesion count were detected for both $\%$ area necrotic+chlorotic and $\%$ area necrotic, with both relationships being best described by two-factor linear regression equations that took into account actual area and lesion count, such that overestimation was inversely related to the natural $\log$ of the actual area (i.e., overestimation of area was greatest at lower severities), with some visual assessments being directly influenced by number of lesions: leaves with greater counts of lesions (but same actual area infected) tended to have the greatest overestimate of severity. The relationship was best described by actual number of lesions for \% area necrotic+chlorotic, and by log actual number of lesions for $\%$ area necrotic. The regression solutions were poor to moderate for both $\%$ area necrotic+chlorotic $\left(r^{2}=0.08\right.$ to 0.57$)$ and $\%$ area necrotic ( $r^{2}$ of 0.16 to 0.69). The GLM analysis showed that the assessment, rater, and actual area necrotic+chlorotic directly affected the visual assessment. In addition, the two-way interactions of lesion count $*$ rater and actual area necrotic+chlorotic * rater were significant. For $\%$ area necrotic, the single factor of lesion count directly affected visual estimates of area, and there were interactions between rater $*$ assessment and lesion count $*$ area necrotic. Some three-way interactions were also significant (data not shown).

Characteristics of the disease estimates within and among assessments. The relationships among and within methods and raters showed various characteristics. Bland-Altman plots of the agreement within assessment types between assessment 1 and 2 consistently showed that IA provided the most repeatable system for assessments of lesion count (Fig. 4), \% area necrotic+chlorotic (Fig. 5), and \% area necrotic (Fig. 6). IA showed no tendency to over- or under-estimate, although the variation for all measures of disease severity show a minor increase with the magnitude of the severity; all VRs consistently showed a marked tendency to greater variation with increasing magnitude of severity. Indeed, VRs also exhibited much greater $95 \%$ levels of agreement for all symptom types, and occasionally demonstrated marked propensity to overor under-estimate values based on the previous assessment (for example, lesion counts by VR3 tended to exhibit propor- tional error in the second assessment at higher lesion counts, while VR1 showed a tendency to overestimate the $\%$ area necrotic+chlorotic in the repeat assessment. Visual assessments of the \% area necrotic and the $\%$ area necrotic+chlorotic consistently demonstrated greater variation in repeatability at greater disease severity. For $\%$ area necrotic+chlorotic, diseased area $<15$ to $20 \%$ was generally more reproducible. The visual estimates of $\%$ area necrotic also showed increasing error at disease severities $>5$ to $10 \%$, with errors increasing above this level. Thus, according to the Bland-Altman plots, all repeat estimates of disease at low severity were more repeatable than at more severe disease levels.

With increasing actual severity, the estimate of lesion counts by VRs became progressively less precise: the variation of the VR ratings was dependent on the magnitude of the actual lesion number in both A1 and A2 (Fig. 7). This was true for $\%$ area necrotic+chlorotic (Fig. 8) and \% area necrotic (Fig. 9). VRs also showed a variable tendency to over- or under-estimate, particularly evident at greater severities (VR2 tended to underestimate more severe

Table 3. Regression analysis and general linear model (GLM) of the relationship ${ }^{\mathrm{a}}$ between actual ${ }^{\mathrm{b}}$ and perceived area infected with symptoms of citrus canker on grapefruit for three visual raters on two separate assessment occasions for $\%$ area necrotic+chlorotic and $\%$ area necrotic

\begin{tabular}{|c|c|c|c|c|c|c|}
\hline & & Assessor & $a^{\mathbf{c}}$ & $b$ & $c$ & $r^{2 \mathrm{~d}}$ \\
\hline \multirow[t]{14}{*}{$\%$ area necrotic+chlorotic } & \multirow[t]{3}{*}{ Assmnt 1} & VR1 & 0.13 & $1.61^{* * *}$ & & 0.80 \\
\hline & & VR2 & $2.61 * * *$ & $0.72 * * *$ & & 0.77 \\
\hline & & VR3 & 0.91 & $1.07 *$ & & 0.83 \\
\hline & \multirow[t]{4}{*}{ Assmnt 2} & VR1 & $1.28^{*}$ & $0.87 * * *$ & & 0.75 \\
\hline & & VR2 & -0.13 & $0.87 * * *$ & & 0.76 \\
\hline & & VR3 & $1.83 * *$ & $1.19 * * *$ & & 0.80 \\
\hline & & & df & MS & & $P>F$ \\
\hline & \multirow{7}{*}{ GLM $^{\mathrm{e}}$} & Assessment $(\mathrm{N})$ & 1 & 20.8 & & 0.36 \\
\hline & & Assessor (A) & 2 & 25.3 & & 0.36 \\
\hline & & Actual area necrotic+chlorotic (ANC) & 1 & $1.1 \times 10^{5}$ & & $<0.0001$ \\
\hline & & $A \times N$ & 2 & 189.9 & & 0.0005 \\
\hline & & $\mathrm{ANC} \times \mathrm{N}$ & 1 & 4.3 & & 0.68 \\
\hline & & $\mathrm{ANC} \times \mathrm{A}$ & 2 & 1132.3 & & $<0.0001$ \\
\hline & & Error & 1,156 & & & \\
\hline \multirow[t]{18}{*}{$\%$ area necrotic } & \multirow[t]{3}{*}{ Assmnt 1} & VR1 & $-0.92 *$ & $2.73 * * *$ & 0.003 & 0.60 \\
\hline & & VR2 & $-1.26^{* *}$ & $3.52 * * *$ & $0.050 * * *$ & 0.64 \\
\hline & & VR3 & $-1.93 * * *$ & $3.75^{* * *}$ & $0.067 * * *$ & 0.73 \\
\hline & \multirow[t]{4}{*}{ Assmnt 2} & VR1 & -0.04 & $2.49 * * *$ & 0.009 & 0.73 \\
\hline & & VR2 & $-1.59 * *$ & $2.85^{* * *}$ & $0.094 * * *$ & 0.66 \\
\hline & & VR3 & $-1.02 * *$ & $3.23 * *$ & $0.021^{*}$ & 0.66 \\
\hline & & & df & MS & & $P>F$ \\
\hline & \multirow{11}{*}{ GLM } & Assessment (N) & 1 & 35.3 & & 0.013 \\
\hline & & Assessor (A) & 2 & 1.5 & & 0.77 \\
\hline & & Actual area necrotic (SqrtAN) & 1 & 3914.6 & & $<0.0001$ \\
\hline & & Actual count of lesions (AL) & 1 & 11.9 & & 0.15 \\
\hline & & $\mathrm{A} \times \mathrm{N}$ & 2 & 8.4 & & 0.23 \\
\hline & & SqrtAN $\times N$ & 1 & 48.7 & & 0.0034 \\
\hline & & $\mathrm{AL} \times \mathrm{N}$ & 1 & 23.5 & & 0.042 \\
\hline & & SqrtAN $\times A$ & 2 & 10.4 & & 0.16 \\
\hline & & $\mathrm{AL} \times \mathrm{A}$ & 2 & 5.1 & & 0.41 \\
\hline & & $\mathrm{AL} \times \mathrm{SqrtAN}$ & 1 & 42.6 & & 0.0062 \\
\hline & & Error & 1,143 & & & \\
\hline
\end{tabular}

\footnotetext{
${ }^{a}$ Where the regression model $y=a+b x$ represents \% area necrotic+chlorotic, and $y=a+b x+c$ Sqrt $z$ represents $\%$ area necrotic, and $a$ is the intercept, $b$ and $c$ are slope parameters, respectively, $x$ is the actual area, and $z$ is the count of lesions.

b Actual area measured with image analysis, visual raters are VR1-3.

c $* * *=P<0.001, * *=P<0.01, *=P<0.05$.

d $r^{2}=$ coefficient of determination.

${ }^{\mathrm{e}} \mathrm{GLM}=$ general linear modeling analysis where $\mathrm{df}=$ degrees of freedom, $\mathrm{MS}=$ mean square, and $P=$ probability of the $F$ value.
} 
necrotic symptoms in both assessment 1 and 2, and VR1 tended to overestimate symptoms of necrosis+chlorosis in assessment 1). Of the three symptom types, lesion count was the most reproducible and least prone to bias, followed by $\%$ area necrotic+chlorotic, and the least reproducible was $\%$ area necrotic. For lesion counts, VRs were both accurate and precise at counts $<30$, for $\%$ area necrotic+chlorotic they were best at estimating diseased area $<20 \%$, and for $\%$ area necrotic at diseased areas $<10 \%$.

The magnitude of disease severity and characteristics of the visual estimates. The frequency of discrepancy of direct VR estimates of disease demonstrate that for all measures, lesion count (Fig. 10), $\%$ area necrotic (Fig. 11), and \% area necrotic+ chlorotic (Fig. 12), the frequency of greater discrepancy from the actual (IA) disease increased with magnitude of disease severity category. Fits of the normal probability density functions showed that higher magnitudes of severity were charac-
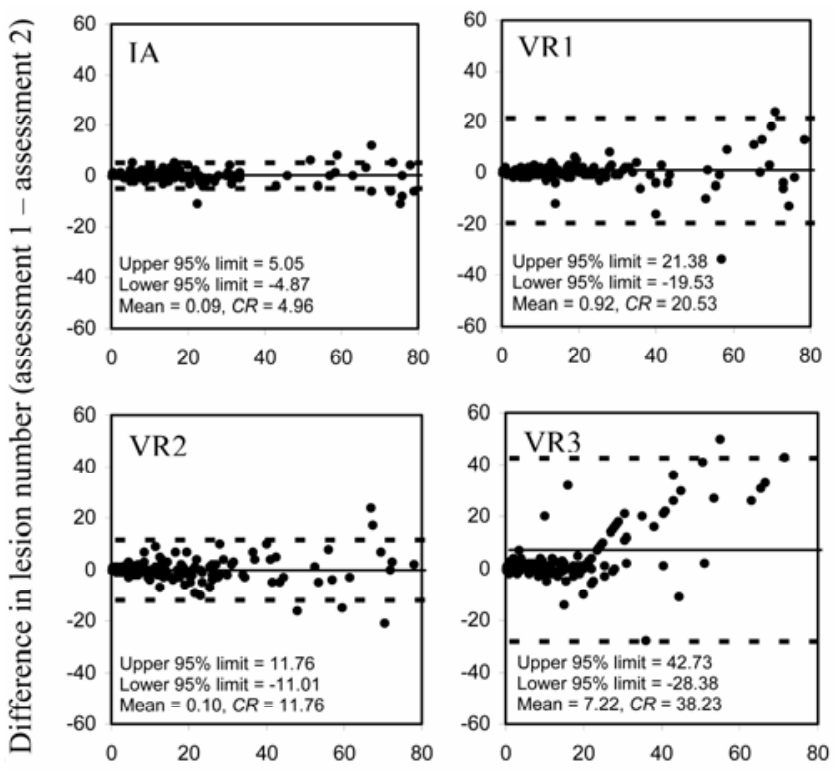

Mean of lesion number assessment 1 and assessment 2

Fig. 4. Bland-Altman plots showing characteristics of repeatability based on two assessments of lesion count by image analysis (IA) and three visual raters (VR1-3). The $95 \%$ limits of agreement are indicated.

Table 4. Regression analysis and general linear model (GLM) of the relationship ${ }^{\mathrm{a}}$ between the ratio of the perceived disease area:actual disease area and actual $^{\mathrm{b}}$ disease area for symptoms of citrus canker on grapefruit for three visual raters on two separate assessment occasions for $\%$ area necrotic+chlorotic and $\%$ area necrotic

\begin{tabular}{|c|c|c|c|c|c|c|}
\hline & & Assessor & $a^{\mathbf{c}}$ & $b$ & $c$ & $r^{2 \mathrm{~d}}$ \\
\hline \multirow[t]{18}{*}{$\%$ area necrotic+chlorotic } & \multirow[t]{3}{*}{ Assmnt 1} & VR1 & $3.19 * * *$ & $-0.71 * * *$ & 0.074 & 0.14 \\
\hline & & VR2 & $3.31 * * *$ & $-0.75^{* * *}$ & 0.002 & 0.29 \\
\hline & & VR3 & $3.51 * * *$ & $-0.81 * * *$ & 0.005 & 0.22 \\
\hline & \multirow[t]{4}{*}{ Assmnt 2} & VR1 & $4.97 * * *$ & $-1.34 * * *$ & $0.005 *$ & 0.57 \\
\hline & & VR2 & $4.38 * * *$ & $-1.26 * * *$ & $0.011 * *$ & 0.44 \\
\hline & & VR3 & $3.44 * * *$ & $-0.67 * * *$ & 0.002 & 0.08 \\
\hline & & & df & MS & & $P>F$ \\
\hline & \multirow{11}{*}{$\mathrm{GLM}^{\mathrm{e}}$} & Assessment $(\mathrm{N})$ & 1 & 5.7 & & 0.0013 \\
\hline & & Assessor (A) & 2 & 4.0 & & 0.025 \\
\hline & & Actual area necrotic+chlorotic $(\log \mathrm{ANC})$ & 1 & 29.9 & & $<0.0001$ \\
\hline & & Actual count of lesions (AL) & 1 & 0.03 & & 0.83 \\
\hline & & $\mathrm{A} \times \mathrm{N}$ & 2 & 1.3 & & 0.09 \\
\hline & & $\log \mathrm{ANC} \times \mathrm{N}$ & 1 & 5.0 & & 0.0026 \\
\hline & & $\mathrm{AL} \times \mathrm{N}$ & 1 & 0.01 & & 0.88 \\
\hline & & $\log \mathrm{ANC} \times \mathrm{A}$ & 2 & 1.7 & & 0.046 \\
\hline & & $\mathrm{AL} \times \mathrm{A}$ & 2 & 1.7 & & 0.043 \\
\hline & & $\mathrm{AL} \times \log \mathrm{ANC}$ & 1 & 0.02 & & 0.86 \\
\hline & & Error & 1,135 & & & \\
\hline \multirow[t]{18}{*}{$\%$ area necrotic } & \multirow[t]{3}{*}{ Assmnt 1} & VR1 & $5.44 * * *$ & $-1.73 * * *$ & 0.17 & 0.28 \\
\hline & & VR2 & $6.43 * * *$ & $-2.33 * * *$ & $1.13 * * *$ & 0.33 \\
\hline & & VR3 & $6.14 * * * *$ & $-2.15^{* * *}$ & $0.93^{*}$ & 0.16 \\
\hline & \multirow[t]{4}{*}{ Assmnt 2} & VR1 & $7.05 * * *$ & $-2.18 * * *$ & 0.01 & 0.69 \\
\hline & & VR2 & $6.99 * * *$ & $-2.83 * * *$ & $1.55^{* * * *}$ & 0.54 \\
\hline & & VR3 & $4.28 * * *$ & $-1.00 * * *$ & -0.13 & 0.25 \\
\hline & & & df & MS & & $P>F$ \\
\hline & \multirow[t]{11}{*}{ GLM } & Assessment $(\mathrm{N})$ & 1 & 1.7 & & 0.29 \\
\hline & & Assessor (A) & 2 & 1.4 & & 0.41 \\
\hline & & Actual area necrotic $(\log \mathrm{AN})$ & 1 & 0.4 & & 0.60 \\
\hline & & Actual count of lesions (logAL) & 1 & 70.9 & & $<0.0001$ \\
\hline & & $\mathrm{A} \times \mathrm{N}$ & 2 & 16.2 & & $<0.0001$ \\
\hline & & $\log \mathrm{AN} \times \mathrm{N}$ & 1 & 1.2 & & 0.37 \\
\hline & & $\log A L \times N$ & 1 & 0.3 & & 0.64 \\
\hline & & $\log \mathrm{AN} \times \mathrm{A}$ & 2 & 0.5 & & 0.73 \\
\hline & & $\log A L \times A$ & 2 & 3.6 & & 0.10 \\
\hline & & $\log \mathrm{AL} \times \log \mathrm{AN}$ & 1 & 61.7 & & $<0.0001$ \\
\hline & & Error & 1,134 & & & \\
\hline
\end{tabular}

${ }^{a}$ Where the regression model $y=a+b \log x+c z$ represents \% area necrotic+chlorotic, and $y=a+b \log x+c \log z$ represents \% area necrotic, and $a$ is the intercept, $b$ and $c$ are slope parameters, respectively, $x$ is the actual area, and $z$ is the count of lesions.

${ }^{\mathrm{b}}$ Actual area measured with image analysis, visual raters are VR1-3.

$\mathrm{c} * * *=P<0.001, * *=P<0.01, *=P<0.05$.

${ }^{\mathrm{d}} r^{2}=$ coefficient of determination.

${ }^{\mathrm{e}} \mathrm{GLM}=$ general linear modeling analysis where $\mathrm{df}=$ degrees of freedom, $\mathrm{MS}=$ mean square, and $P=$ probability of the $F$ value. 

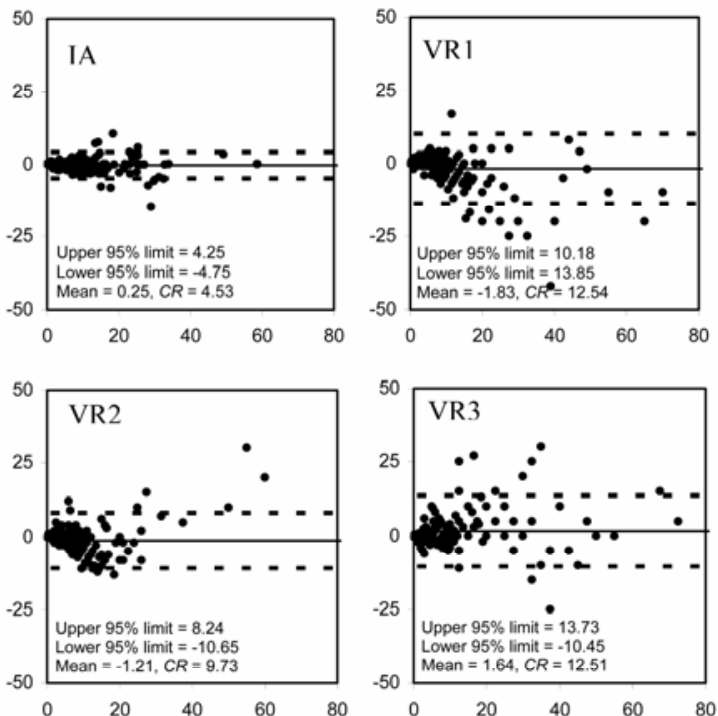

Mean of $\%$ area necrotic+chlorotic assessment 1 and assessment 2

Fig. 5. Bland-Altman plots showing characteristics of repeatability based on two assessments of \% area necrotic+chlorotic by image analysis (IA) and three visual raters (VR1-3). The 95\% limits of agreement are indicated.
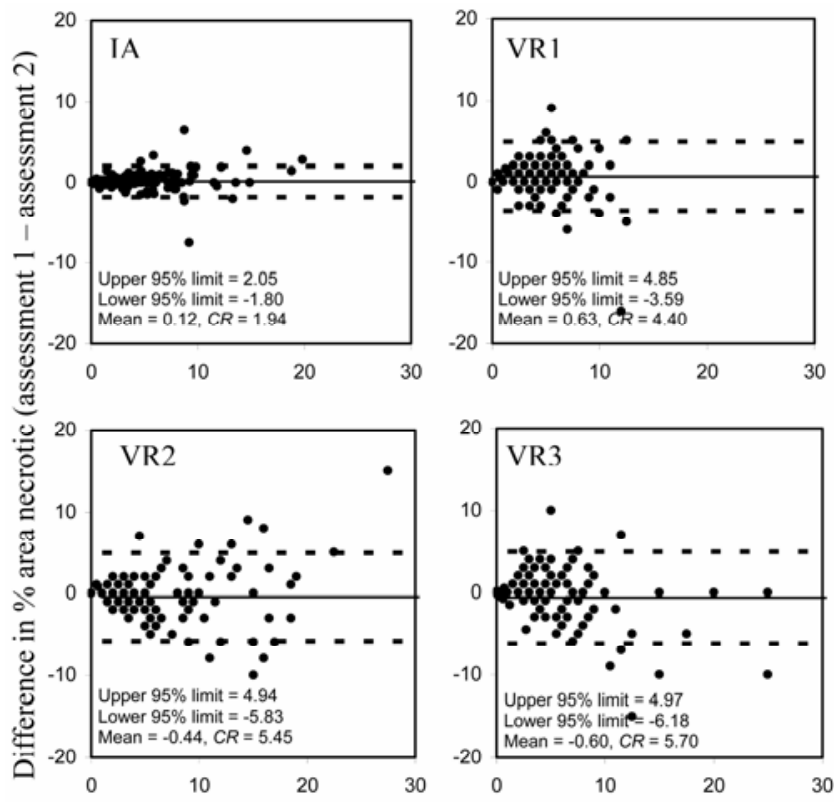

Mean of $\%$ area necrotic assessment 1 and assessment 2

Fig. 6. Bland-Altman plots showing characteristics of repeatability based on two assessments of \% area necrotic by image analysis (IA) and three visual raters (VR1-3). The 95\% limits of agreement are indicated.

\section{Assessment 1}
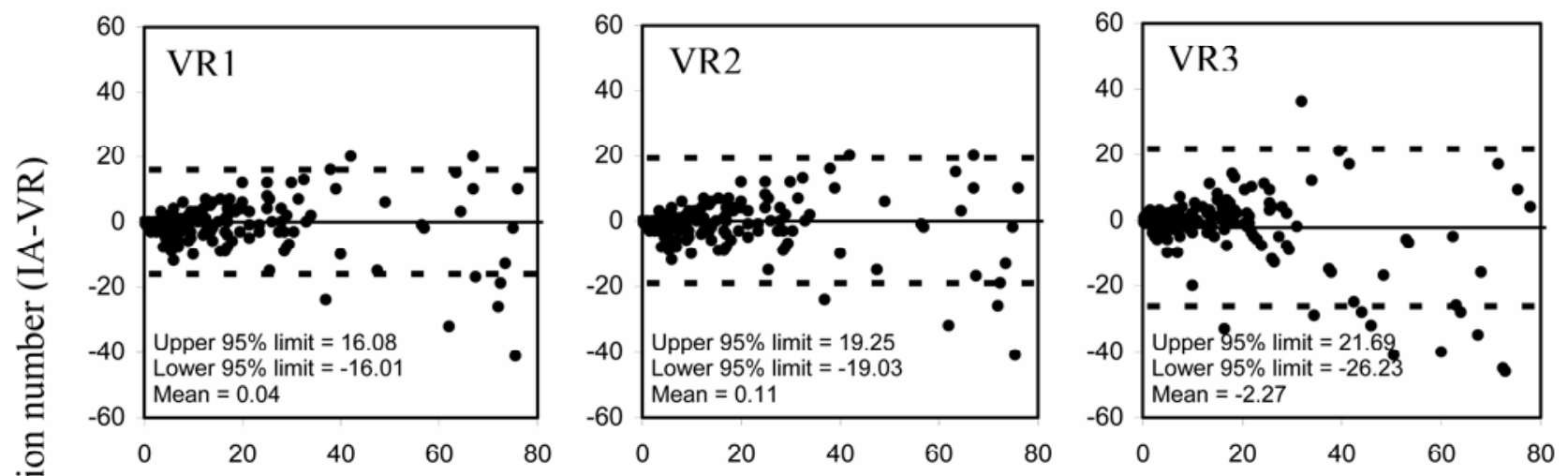

\section{Assessment 2}
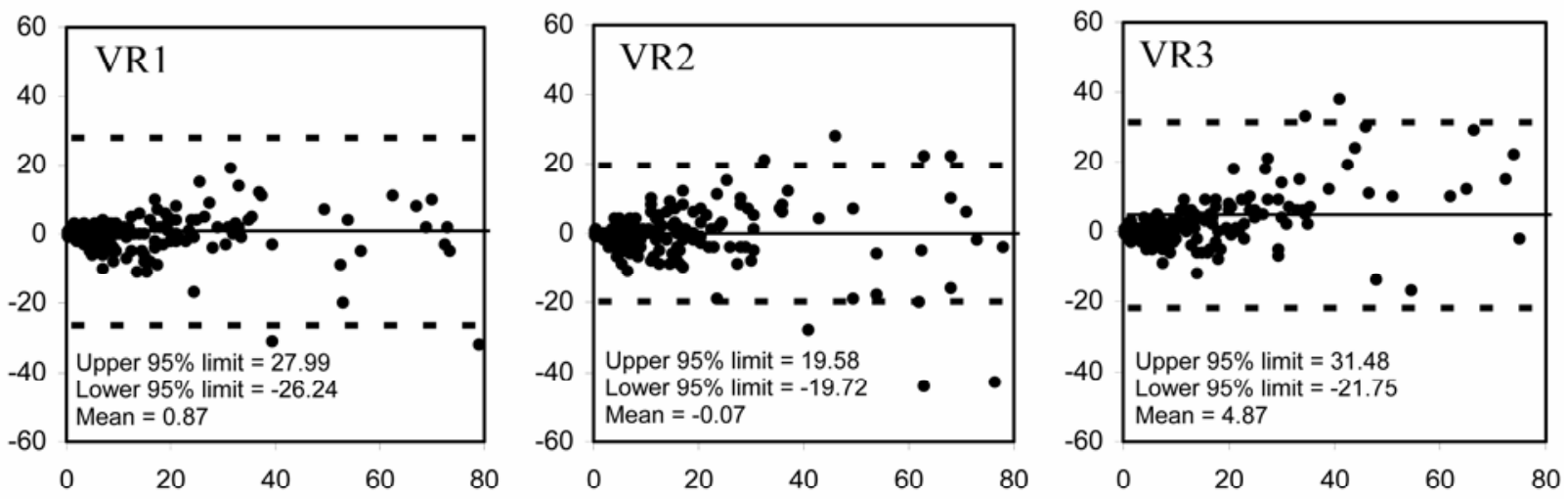

\section{Mean of lesion number}

Fig. 7. Bland-Altman plots showing characteristics of reproducibility for lesion counts by three visual raters (VR1-3) compared with actual values from image analysis on two assessment occasions. The $95 \%$ limits of agreement are indicated. 
terized by long tails and relatively flat peaks; while at low severity the probability was steeply bell-shaped with short, steep tails. The $t$ test showed that estimates of $\mu$ for area infected were similar: at low levels of disease, $\mu$ was overestimated, but above 10 to $15 \%, \mu$ was no longer significantly different from zero (Table 5). Furthermore, the $\sigma$ of the discrepancy indicated the dispersion of the difference around zero was consistently least for the lowest disease category, and greater severity of disease resulted in a consistent increase in $\sigma$ for all symptom types. Although kurtosis was consistently leptokurtic, it was most extreme over the lower ranges for measures of $\%$ area infected where the occurrence of extreme values was infrequent. Kurtosis lessened as actual \% area infected increased and the frequency of extreme values became more common (for $\%$ area necrotic+chlorotic kurtosis was 17.92 at 0 to $10 \%$ and 0.22 at 30 to $40 \%$, respectively). Kurtosis for lesion count did not show a consistent pattern over the range examined, but estimates of lesion count probably rely on a different system of mental computation than those for estimating $\%$ area, which is based on ratios
$(2,3,26)$. For all measures, the skew was consistently negative, or left skewed, implying that there was an overall tendency among these three raters to overestimate disease. Lesion number was inconsistent, but estimates of $\%$ area infected demonstrated most severe skew in categories close to zero: it is not possible to assess disease as negative counts or negative area. Indeed, the K-S and A-D tests showed that the normal distribution was only an approximation of the data distribution at low lesion counts or low disease severities, but at lesion counts $>30$ and $\%$ area necrotic $>12 \%$ and $\%$ area necrotic+chlorotic $>30 \%$, the normal distribution described these data well.

White's test showed that these data were highly heteroscedastic: the residual variance from the regression model was not constant with actual disease for lesion count, $\%$ area necrotic+chlorotic, or $\%$ area necrotic (Table 6). This change in residual variance with increasing disease severity is reflected in the variance of the combined estimates across raters and assessment number for each leaf, at least over the disease ranges assessed in this study (Fig. 13A to C, Table 7). Due to the heteroscedasticity, a log-log scale (log variance $[Y]$ against log actual disease $[X]$ ) $b$ best represented the data $\left(r^{2}=0.65\right.$ to 0.74). The log-log plot is a linearization of the general power law model:

$y=a x^{b}$

deriving the linear form:

$\log y=\log \left(a x^{b}\right)$

$\log y=\log a+\log x^{b}$

(since $\log p q=\log p+\log q$ )

Therefore:

$\log y=\log a+b \log x\left(\right.$ since $\left.\log x^{b}=b \log x\right)$

The log-log plot thus has a gradient $b$ (the exponent of the power function), and intercept on the $\log y$ axis of $\log a$ (the constant). Thus, over the disease severities assessed, the variance of the estimates of citrus canker severity exhibited a powerlaw relationship with the actual disease (rather than the estimate itself, which as already demonstrated, has a linear relationship with actual disease). The implication is that overall direct estimates of more severe disease are accompanied by increased error, at least over the disease

\section{Assessment 1}

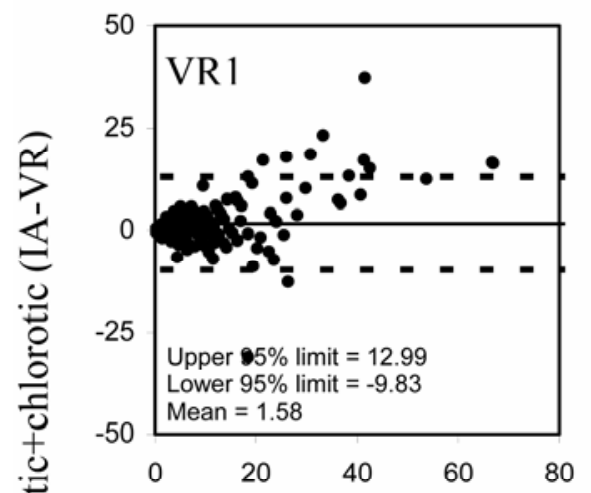

\section{Assessment 2}

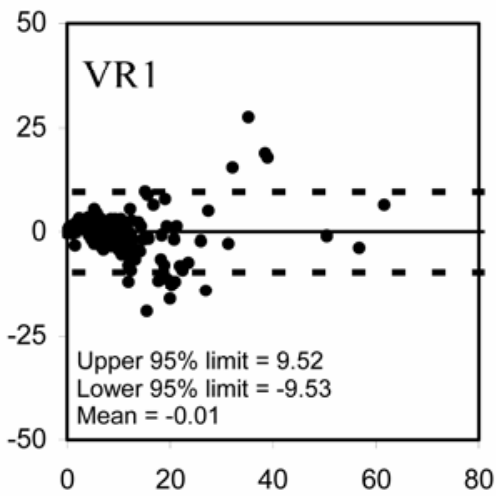

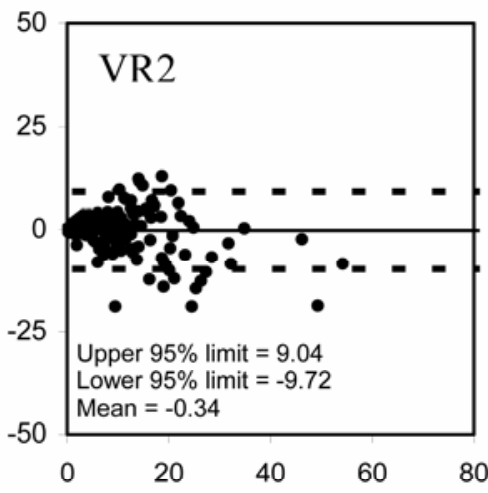

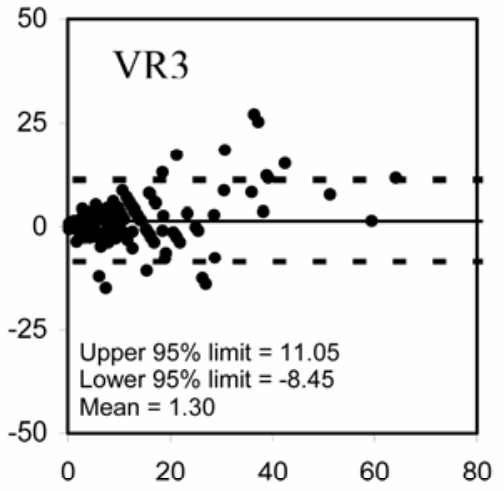

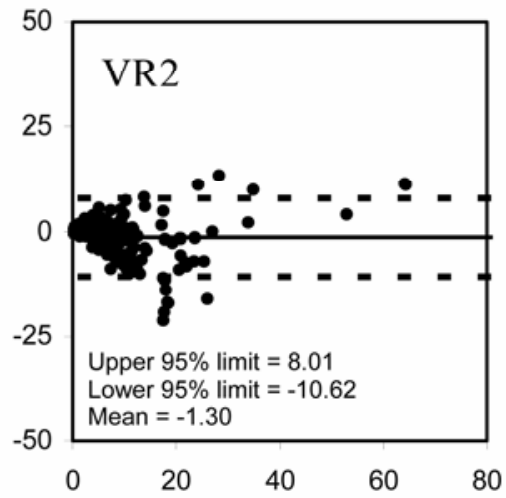

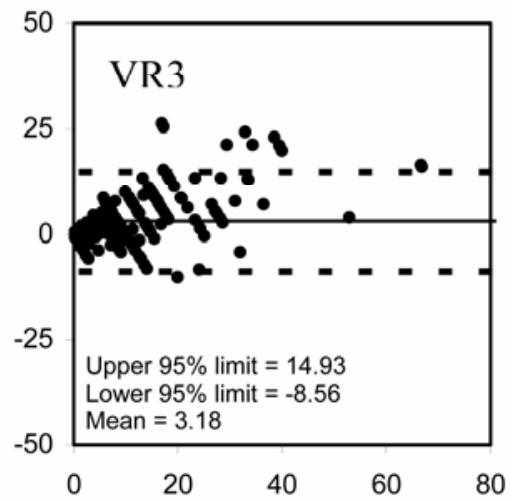

\section{Mean of $\%$ area necrotic+chlorotic}

Fig. 8. Bland-Altman plots showing characteristics of reproducibility for estimates of \% area necrotic+chlorotic by three visual raters (VR1-3) compared with actual values from image analysis on two assessments occasions. The $95 \%$ limits of agreement are indicated. 


\section{Assessment 1}
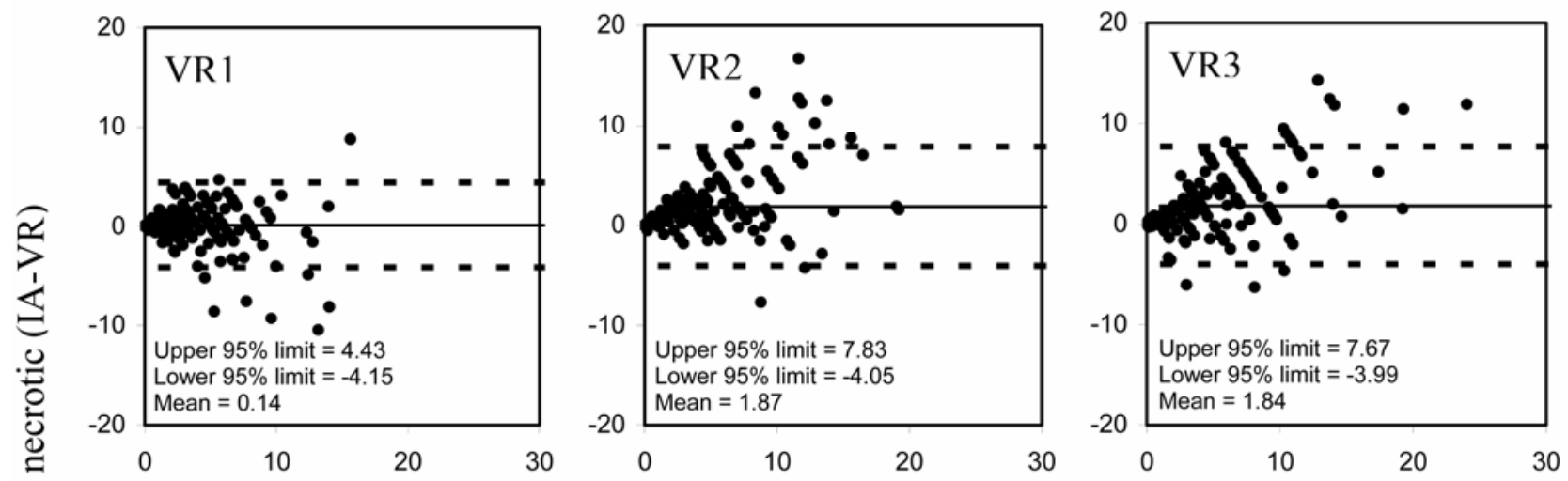

\section{Assessment 2}
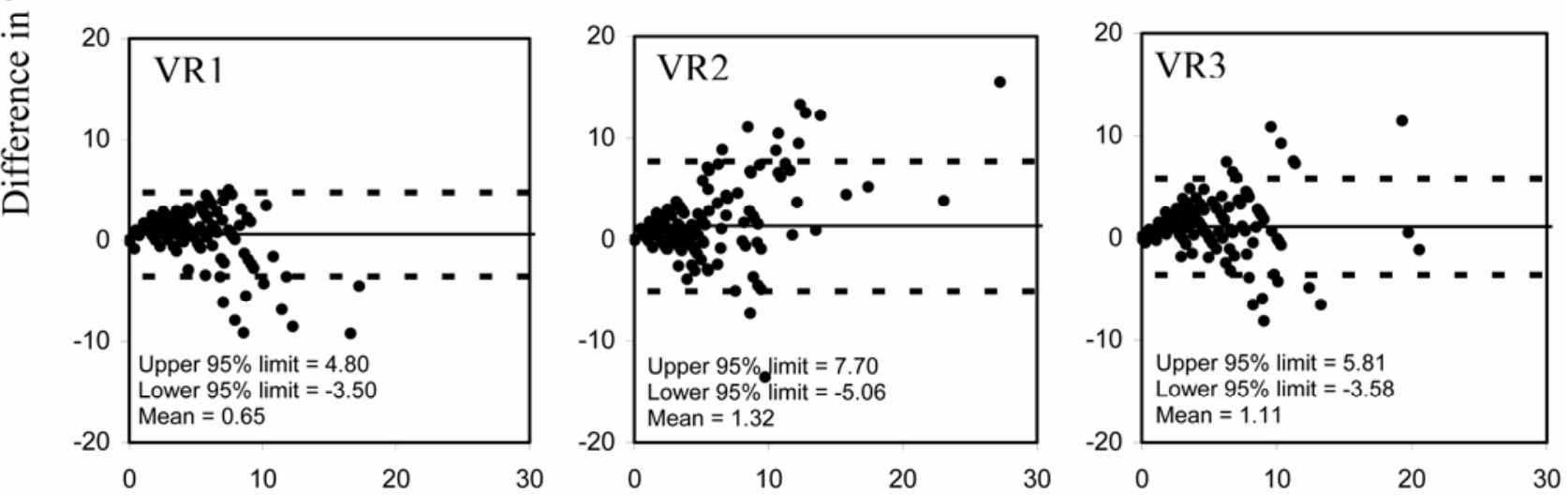

Mean of $\%$ area necrotic

Fig. 9. Bland-Altman plots showing characteristics of reproducibility for estimates of $\%$ area necrotic by three visual raters (VR1-3) compared with actual values from image analysis on two assessment occasions. The $95 \%$ limits of agreement are indicated.
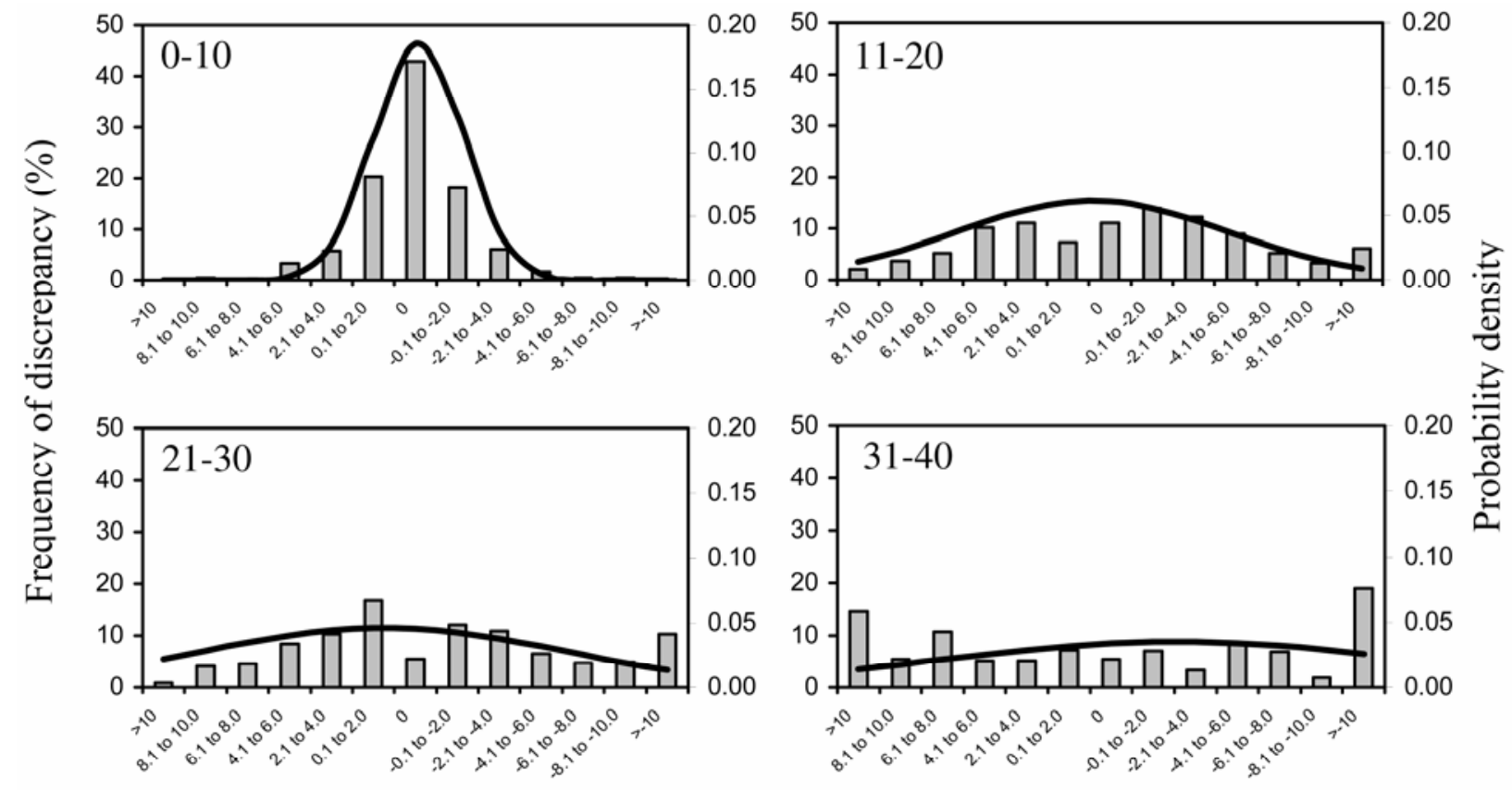

Discrepancy of the visual estimate - actual number of lesions

Fig. 10. Frequencies and magnitudes of discrepancies of visual counts from the actual count of lesions of citrus canker across different ranges of disease (0 to 10,11 to 20,21 to 30 , and 31 to 40 lesions per leaf as measured using image analysis). Normal probability density functions are fit to the data. Characteristics and statistics for these functions are shown in Table 7. Data are combined for three visual raters on two separate assessments. 

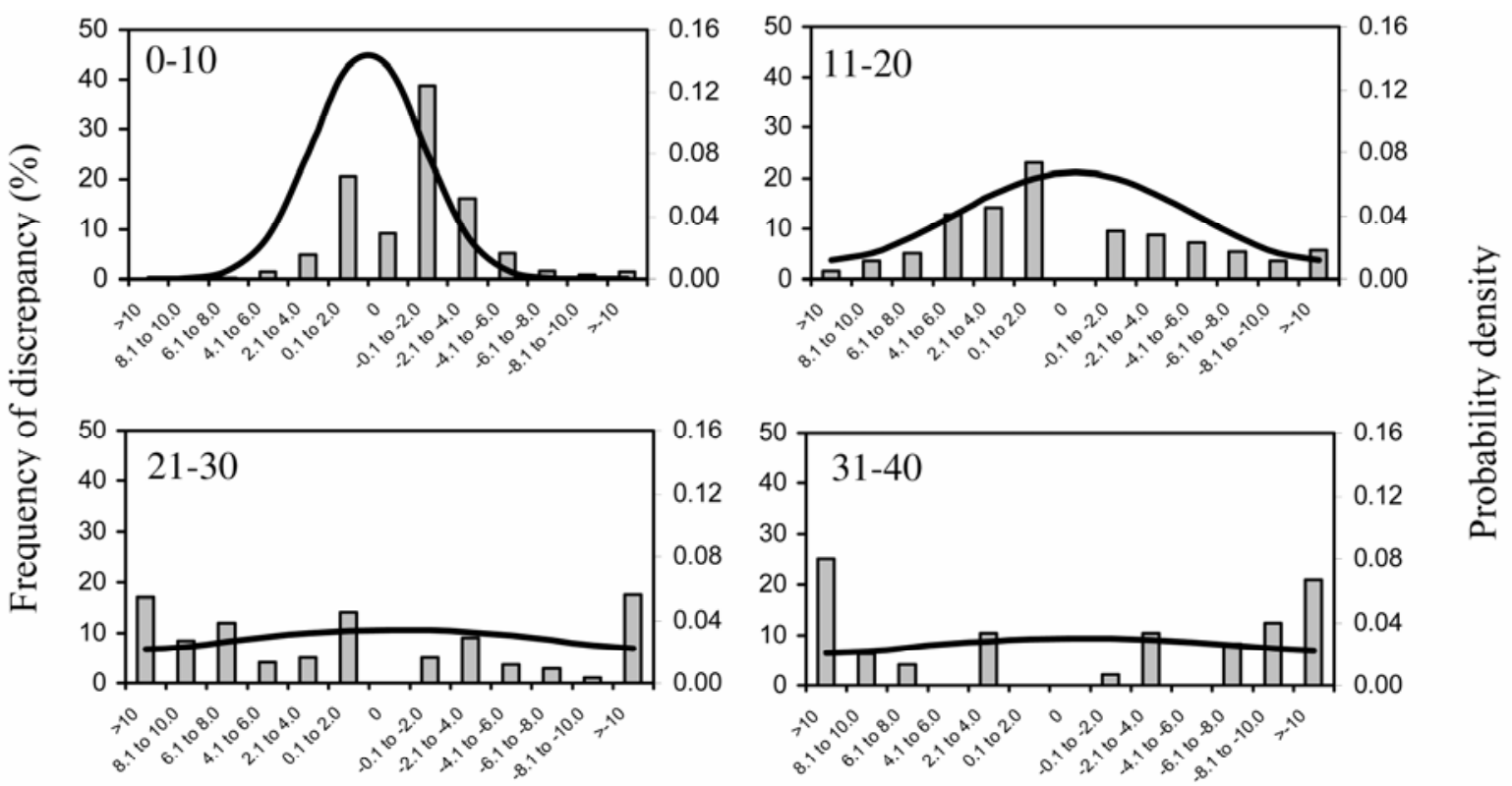

Discrepancy of the visual estimate - actual \% area chlorotic+necrotic

Fig. 11. Frequencies and magnitudes of discrepancies of visual estimates from the actual $\%$ area necrotic+chlorotic with citrus canker across different ranges of disease (0 to 10, 11 to 20,21 to 30 , and 31 to $40 \%$ leaf area infected as measured using image analysis). Normal probability density functions are fit to the data. Characteristics and statistics for these functions are shown in Table 7. Data are combined for three visual raters on two separate assessments.
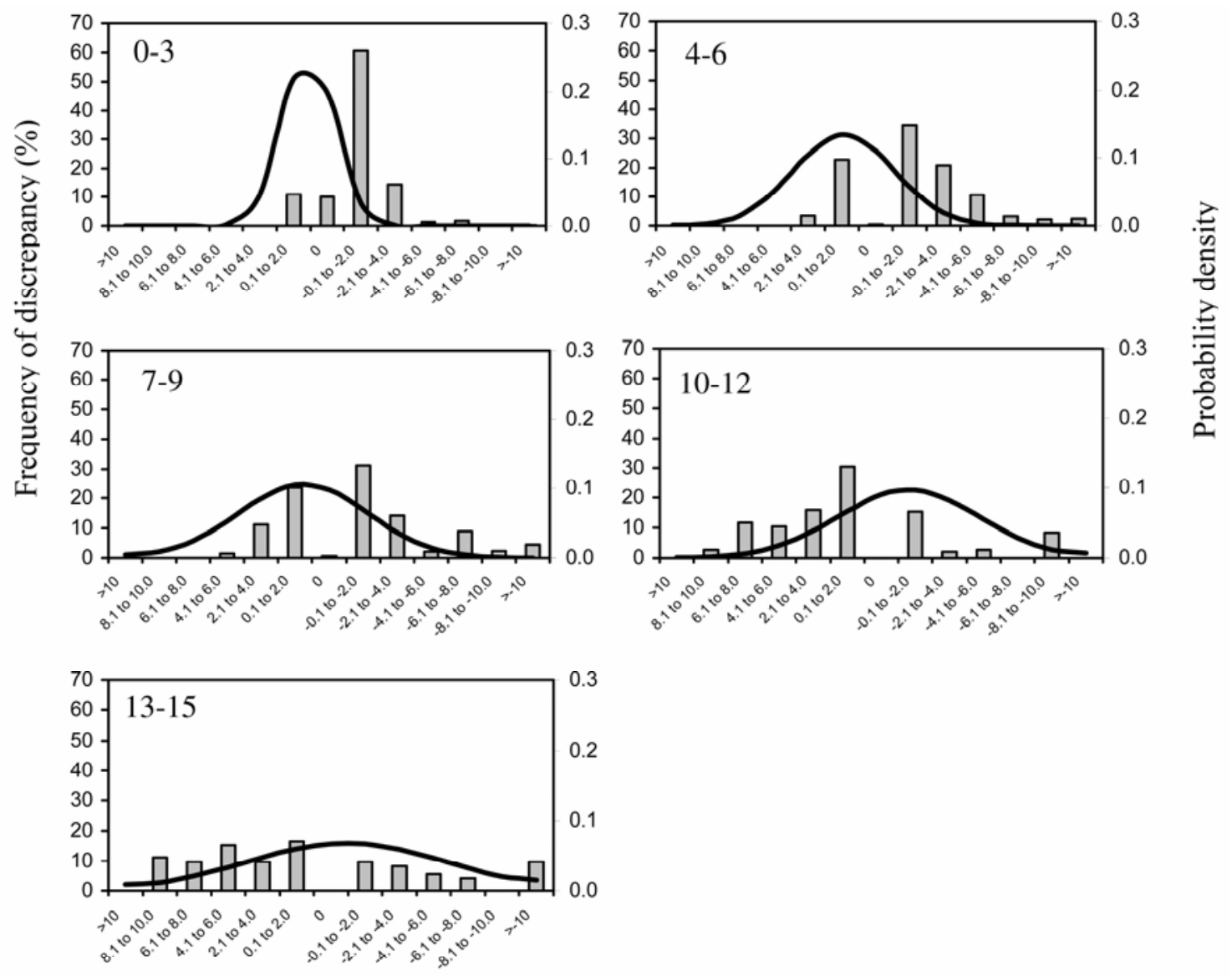

Discrepancy of the visual estimate - actual \% area necrotic

Fig. 12. Frequencies and magnitudes of discrepancies of visual estimates from the actual \% area necrotic with citrus canker across different ranges of disease ( 0 to 3,4 to 6,7 to 9,10 to 12,13 to $15 \%$ leaf area infected as measured using image analysis). Normal probability density functions are fit to the data. Characteristics and statistics for these functions are shown in Table 7. Data are combined for three visual raters on two separate assessments. 
ranges measured in this study. These data also suggest that the variance of visual estimates increases in a curvilinear fashion with increases in actual severity of citrus canker.

\section{DISCUSSION}

There was a variable relationship among the different symptom components of citrus canker. Thus, lesion counts did not relate particularly closely to the $\%$ area necrotic or the \% area necrotic+chlorotic, suggesting lesion size and count was highly variable among leaves. Sherwood et al. (33) has already noted how lesion size varies and how this might influence estimates of diseased area, leading to incorrect judgments. However, even the relationship between $\%$ area necrotic and \% area necrotic+chlorotic was not particularly good, suggesting lesion characteristics were variable. Indeed, this was true whether symptoms of actual disease were being compared (IA ratings) or those of the rater estimates. If similar-aged leaves with entirely uniform lesion ages had been used, better relationships between the various severity measures might have been ob- served. Particularly young (water-soaked spots) and old lesions (shot-holes) were avoided in this study, a range of lesions that represented the bulk of infection on young mature and mature-aged leaves were grouped together and assessed, and they did display different degrees of necrosis and chlorosis, perhaps influencing the relationships between these measures of severity. Also, the counts of lesions and their distribution on the leaf may affect the area showing symptoms (lesions may affects each other's growth and development), which was not investigated in this study. In many assessment situations, both leaf and lesion age will vary, and these results highlight the importance of measuring the appropriate symptom type for the purpose of the research, whether it is infection frequency (lesion counts) or symptom area estimates.

Overall, there was a marked tendency to overestimate diseased area at low severity. The relationship between visual:actual area spotted and actual area spotted showed that for both $\%$ area necrotic+chlorotic and \% area necrotic, VRs overestimation of disease was inversely related to the actual area (i.e., lower disease was overestimated more). The tendency to overestimate area at low disease severity has been noted before for plant disease $(1,33)$; in psychophysical tests, overestimation of area has also been observed, but the relationship appears to be complex and poorly understood $(2,14)$. With estimates of $\%$ area necrotic (but not \% area necrotic+ chlorotic), some raters found that greater lesion counts also resulted in overestimates of diseased area. Thus, lesions appear to cover more area than they actually do, which is most pronounced at low lesion counts. At the same time, leaves with more lesions tend to be assessed as having greater area infected compared with leaves with fewer lesions but an equal actual area infected, confirming two previous observations on leaf spotting diseases $(1,33)$. With citrus canker, these observations held true for $\%$ area necrotic, but the overestimation of area was not significant for $\%$ area necrotic+chlorotic. The reason for this difference is not clear, but perhaps the more diverse and complex lesions (necrotic+ chlorotic) obscured some effects of lesion count.

Table 5. Parameters of the normal distribution for different actual disease severity category ranges of the discrepancy of visual estimates from the actual value of severity (measured by image analysis) for symptoms of citrus canker on grapefruit leaves

\begin{tabular}{|c|c|c|c|c|c|c|c|c|c|}
\hline Assessment & $\begin{array}{c}\text { Actual } \\
\text { disease range } \\
\end{array}$ & $\begin{array}{l}\text { Rater } \\
\text { range }\end{array}$ & $\mathbf{N}^{\mathbf{a}}$ & $\mu^{\mathbf{b}}$ & $t$ test $^{\mathrm{c}}$ & $\sigma^{\mathrm{d}}$ & $\beta_{2}{ }^{\mathrm{e}}$ & $\gamma_{1}{ }^{\mathrm{f}}$ & $\begin{array}{l}\text { K-S (A-D) tests } \\
\text { for normality }\end{array}$ \\
\hline Lesion no. & $\begin{array}{l}10(0-10) \\
10(11-20) \\
10(21-30) \\
10(31-40)\end{array}$ & $\begin{array}{l}21 \\
41 \\
32 \\
66\end{array}$ & $\begin{array}{r}681 \\
246 \\
126 \\
57\end{array}$ & $\begin{array}{r}0.10 \\
-0.80 \\
-1.93 \\
-0.67\end{array}$ & $\begin{array}{l}0.27 \\
0.07 \\
0.01 \\
0.68\end{array}$ & $\begin{array}{r}2.23 \\
6.81 \\
8.40 \\
11.95\end{array}$ & $\begin{array}{l}4.33 \\
4.48 \\
7.53 \\
0.60\end{array}$ & $\begin{array}{l}-0.11 \\
-1.14 \\
-2.06 \\
-0.16\end{array}$ & $\begin{array}{l}<0.01(<0.005) \\
<0.01(<0.005) \\
<0.01(<0.005) \\
>0.15(>0.25)\end{array}$ \\
\hline$\%$ area necrotic+chlorotic & $\begin{array}{l}10(0-10) \\
10(11-20) \\
10(21-30) \\
10(31-40)\end{array}$ & $\begin{array}{l}18.3 \\
32.3 \\
56.3 \\
57.2\end{array}$ & $\begin{array}{r}845 \\
261 \\
102 \\
30\end{array}$ & $\begin{array}{r}-1.02 \\
-0.02 \\
0.24 \\
0.66\end{array}$ & $\begin{array}{c}<0.0001 \\
0.96 \\
0.84 \\
0.77\end{array}$ & $\begin{array}{r}2.74 \\
5.90 \\
11.70 \\
13.35\end{array}$ & $\begin{array}{r}17.92 \\
1.18 \\
0.51 \\
0.22\end{array}$ & $\begin{array}{l}-2.62 \\
-0.64 \\
-0.88 \\
-0.88\end{array}$ & $\begin{array}{l}<0.01(<0.005) \\
<0.01(<0.005) \\
<0.01(<0.005) \\
<0.14(0.12)\end{array}$ \\
\hline$\%$ area necrotic & $\begin{array}{l}3(0-3) \\
3(4-6) \\
3(7-9) \\
3(10-12) \\
3(13-15)\end{array}$ & $\begin{array}{l}14.7 \\
20.0 \\
17.7 \\
21.8 \\
20.6\end{array}$ & $\begin{array}{r}747 \\
291 \\
135 \\
42 \\
21\end{array}$ & $\begin{array}{r}-1.13 \\
-1.88 \\
-1.53 \\
1.59 \\
0.91\end{array}$ & $\begin{array}{c}<0.0001 \\
<0.0001 \\
<0.0001 \\
0.017 \\
0.50\end{array}$ & $\begin{array}{l}1.55 \\
2.97 \\
3.79 \\
4.11 \\
5.84\end{array}$ & $\begin{array}{r}11.13 \\
4.22 \\
1.05 \\
0.91 \\
0.11\end{array}$ & $\begin{array}{l}-2.64 \\
-1.56 \\
-1.03 \\
-0.81 \\
-0.76\end{array}$ & $\begin{array}{l}<0.01(<0.005) \\
<0.01(<0.005) \\
<0.01(<0.005) \\
<0.01(0.034) \\
<0.15(>0.25)\end{array}$ \\
\hline
\end{tabular}

a $\mathrm{N}=$ Number of observations in sample.

${ }^{\mathrm{b}} \mu=$ sample mean.

${ }^{\mathrm{c}} t$ test $=$ tests the position of the mean relative to zero.

$\mathrm{d} \sigma=$ standard deviation of the sample.

${ }^{\mathrm{e}} \beta_{2}=$ kurtosis measures how amplitude of the peak compares with the tails of the probability distribution, higher values denoting occurrence of infrequent, extreme values.

${ }^{\mathrm{f}} \gamma_{1}=$ skewness of the distribution which is a measure of the asymmetry of the probability distribution.

g The Kolmogorov-Smirnov (K-S) and Anderson-Darling (A-D) tests for normality. The latter is a modification of the K-S test but gives more weight to the tails, whereas the K-S test is distribution free. The A-D test uses the specific distribution in calculating critical values, which makes for a more sensitive test.

Table 6. White's test of heteroscedasticity for regression between the actual severity and the visual estimate by three assessors on two assessment dates for lesion count, $\%$ area necrotic, and $\%$ area necrotic+chlorotic

\begin{tabular}{|c|c|c|c|c|c|c|}
\hline \multicolumn{4}{|c|}{ Regression analysis of estimate against actual disease ${ }^{a}$} & \multicolumn{3}{|c|}{ White's test for heteroscedasticity } \\
\hline Variable & $a^{\mathbf{b}}$ & $b^{\mathbf{c}}$ & $r^{2 \mathrm{~d}}$ & df & Chi-square & $P^{\mathbf{e}}$ \\
\hline Lesion count & 0.10 & $1.03 * * *$ & 0.79 & 2 & 51.2 & $<0.0001$ \\
\hline$\%$ area necrotic & $1.60 * * *$ & $0.91 * * *$ & 0.57 & 2 & 80.7 & $<0.0001$ \\
\hline$\%$ area necrotic+chlorotic & $0.89 * *$ & $1.00 * * *$ & 0.74 & 2 & 74.6 & $<0.0001$ \\
\hline
\end{tabular}


A
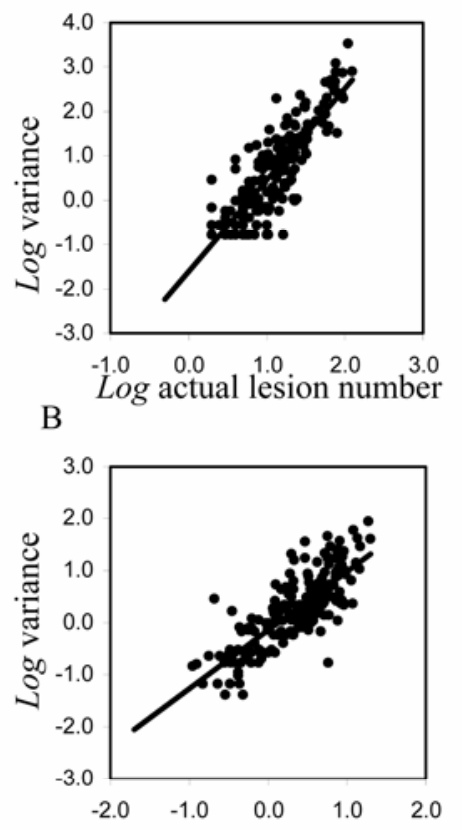

C $\log$ actual \% area necrotic

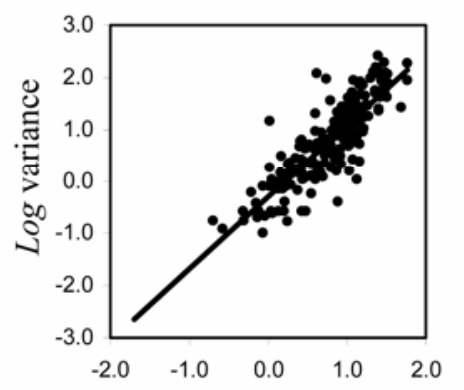

Log actual \% area necrotic+chlororotic

Fig. 13. Relationship between (A) the $\log$ variance of visual lesion counts and actual counts of $\log$ lesion count (B) $\log$ variance of visual estimates of $\%$ area necrotic and $\log$ actual \% area necrotic, (C) $\log$ variance of visual estimates of $\%$ area necrotic+chlorotic and $\log$ actual \% area necrotic+chlorotic. Variances of visual estimates are each based on a total of six estimates of the severity of disease on each leaf taken by three visual raters on two occasions.

The Bland-Altman plots confirmed repeatability and reproducibility of estimates for the different methods (IA versus VRs) and confirmed that IA was the most repeatable method for all symptom types (7). The results showed various characteristics of the visual assessments, including overor under-estimation, heterogeneity of variance, and varying ability to rate actual disease among raters, agreeing with some results shown by Nutter and Schultz (29). Increased variance with more severe citrus canker (and the discrepancy of the estimate from the actual disease) suggested that ability to estimate disease was more accurate and precise at low severities. The systematic change in variance across the disease severity spectrum in this study agrees with the observations found in some other

Table 7. Relationships ${ }^{\mathrm{a}}$ between actual disease and the variance of the visual lesion counts and visual estimates of $\%$ area necrotic and $\%$ area necrotic+chlorotic

\begin{tabular}{lllrc}
\hline Assessment & $\boldsymbol{a}^{\mathbf{b}}$ & $\boldsymbol{b}^{\mathbf{c}}$ & $\boldsymbol{C V}^{\mathbf{d}}$ & $\boldsymbol{r}^{\mathbf{2}}$ \\
\hline Lesion count & $-1.61^{* * *}$ & $2.07^{* * *}$ & 74.1 & 0.71 \\
$\%$ area necrotic & $-0.14^{* *}$ & $1.12^{* * *}$ & 168.6 & 0.63 \\
$\%$ area necrotic+chlorotic & $-0.31^{* * *}$ & $1.38^{* * *}$ & 55.4 & 0.71 \\
\hline
\end{tabular}

a Regression model $y=a+b x$.

${ }^{\mathrm{b}} a=$ intercept; $* * *=P<0.001, * *=P<0.01$.

c $b=$ slope; $* * *=P<0.001$

${ }^{\mathrm{d}} C V=$ coefficient of variability.

e $r^{2}=$ coefficient of determination.

studies $(9,10,13,19)$. However, Nita et al. (24) found no effect of severity magnitude on error in disease estimation, but found leaflet size and lesion number were sources of error with increasing disease severity. Horsfall and Barratt (17) based their assessment scale on the nonexistent Weber-Fechner law, and although that law does not exist, the observations from several studies suggest that variance at disease severity $<25 \%$ is lower than variance between 25 and $75 \%$ disease, and this lends some credence to the observation that ability to accurately and precisely estimate disease by direct assessment depends on changes in visual acuity related to actual disease, or at least to the components of the symptoms that contribute to severity and may affect perception $(9,10,13,19,24)$. Forbes and Jeger (9) showed that estimation error of unaided direct assessments increased up to $25 \%$, but between 25 and $75 \%$ the variance was similar and not in agreement with the H-B scale. Nutter and Esker (26) further demonstrated that the basis of the H-B scale was flawed between 25 and $50 \%$, and thus argued for an additional step in the H-B scale, but unlike Forbes and Jeger (9), they did not investigate disease $<25$ or $>50 \%$. Although the source of the increased variance associated with greater actual disease may be due to a number of factors (including leaf size, lesion size, type, complexity, and number), it was highly significant for all measures of disease severity based on White's test of heteroscedasticity. In addition, there is a curvilinear relationship between the variance of the estimate and actual severity of citrus canker over the range of disease assessed. The majority of diseases exist in the field at severities $<35 \%(21,33)$, so it is really below this level that the relationships need to be understood in the greatest detail, and although a linear relationship seems to describe the relationship between actual and perceived disease $(7,24,29)$, the relationship between the variance of the estimate and the actual disease is less well defined.

Despite all three raters being experienced plant pathologists (combined experience of disease assessment of $\sim 70$ years), there was error in disease estimation. There were also differences in the reproducibility of lesion counts compared with estimates of area diseased. It is likely that different mental processing systems are operating when a count is made compared to when an area is estimated. Not only does this lead to discrepancy between methods, but it may also mean that one method is more accurate and precise, and there is little doubt that lesion counts are more reproducible and repeatable. However, they also take a lot longer to perform, and thus may not be practical except for certain studies where measures of infection frequency are desired (e.g., some epidemiological studies and plant breeding). Perception of disease severity is known to be complex, and several factors appear to influence the perception of citrus canker symptoms. Training has been demonstrated to improve both precision and accuracy across the range of disease severity $(23,26,27,29,30)$. Generally, more experienced raters are more accurate and precise, and disease assessment cards also improve the quality of disease assessment $(4,23,25-$ $27,29,30)$. It would be of interest to know the proportion of studies where disease assessments are made that actually utilize assessment cards as references on a leafby-leaf basis, compared with direct estimation. However, despite the lack of specific training or use of assessment cards in the current study, the quality of the severity assessments was similar to those previously described for citrus canker $(4,7)$.

Assessment of disease by raters inevitably creates error and is influenced by the type and severity of the symptoms. Indeed, raters have several sources of error, not just in perception of complex symptoms and their various components, but also due to subjectivity, loss of concentration, and drifting in methodology. Assessment of citrus canker symptoms shares many of the characteristics of the assessment of other diseases, and doubtless training of raters will improve their ability to estimate disease more accurately and precisely $(4,29)$. An awareness of the relationships and characteristics of disease assessment should be useful in developing and improving disease assessment training.

\section{LITERATURE CITED}

1. Amanat, P. 1976. Stimuli effecting disease assessment. Agric. Conspectus Scientificus 39:27-31.

2. Baird, J.C. 1970. Psychophysical analysis of visual space. Pergamon Press, Oxford.

3. Baird, J. C., and Noma, E. 1978. Fundamentals 
of Scaling and Psychophysics. Wiley, New York.

4. Belasque Junior, J., Bassanezi, R. B., Spósito, M. B., Ribeiro, L. M., de Jesus Júnior, W. C., and Amorim, L. 2005. Escalas diagramáticas para avaliação da severidade do cancro cítrico. Fitopatol. Bras. 30:387-393.

5. Bland, J. M., and Altman, D. G. 1986. Statistical methods for assessing agreement between two methods of clinical measurement. Lancet 68:307-310.

6. Bland, J. M., and Altman, D. G. 1999. Measuring agreement in method comparison studies. Stat. Methods Med. Res. 8:135-160.

7. Bock, C. H., Parker, P. E., Cook, A. Z., Gottwald, T. R. 2008. Visual rating and the use of image analysis for assessing different symptoms of citrus canker on grapefruit leaves. Plant Dis. 92:530-541.

8. Dewitte, K., Fierens, C., Stöckl, D., Thienpont, L. M. 2002. Application of the Bland-Altman plot for interpretation of method-comparison studies: A critical investigation of its practice. Clin. Chem. 48:799-801.

9. Forbes, G. A., and Jeger, M. J. 1987. Factors affecting the estimation of disease intensity in simulated plant structures. Z. Pflanzen Pflanzenschutz 94:113-120.

10. Forbes, G. A., and Korva, J. T. 1994. The effect of using a Horsfall-Barratt scale on precision and accuracy of visual estimation of potato late blight severity in the field. Plant Pathol. 43:675-682.

11. Gaunt, R. E. 1995. The relationship between plant disease and severity and yield. Annu. Rev. Phytopathol. 33:119-144.

12. Gottwald, T. R., Hughes, G., Graham, J. H. Sun, X., and Riley, T. 2001. The citrus canker epidemic in Florida: The scientific basis of regulatory eradication policy for an invasive species. Phytopathology 91:30-34.
13. Hau, B., Kranz, J., and Konig, R. 1989. Fehler beim Schätzen von Befallsstärken bei Pflanzenkrankheiten. Z. Pflanzenkrank. Pflanzen. 96:649-674.

14. Helson, H., and Bevan, W. 1964. An investigation of variables in judgments of relative area. J. Exp. Psychol. 67:335-341.

15. Herbert, T. T. 1982. The rationale for the Horsfall-Barratt plant disease assessment scale. Phytopathology 72:1269.

16. Horsfall, J. G. 1945. Fungicides and their action. Annales Cryptogamica et Phytopathologici, Vol. II. Chronica Botanica, Waltham, MA.

17. Horsfall, J. G., and Barratt, R. W. 1945. An improved grading system for measuring plant disease. (Abstr.) Phytopathology 35:655.

18. Horsfall, J. G., and Cowling, E. B. 1978. Pathometry: The measurement of plant disease. Pages 120-136 in: Plant Disease: An Advanced Treatise, Vol. II. J. G. Horsfall and E. B. Cowling, eds. Academic Press, New York

19. Koch, H., and Hau, B. 1980. Ein psychologischer aspect beim schatzen von pflanzenkrankheiten. Z. Pflanzenkrank. Pflanzen. 87:587-593.

20. Kranz, J. 1970. Schätzklassen für Krankheitsbefall. Phytopathol. Z. 69:131-139.

21. Kranz, J. 1977. A study on maximum severity in plant diseases. Travaux dédiés à G. ViennotBourgin, 169-173.

22. Kranz, J. 1988. Measuring plant disease. Pages 35-50 in: Experimental Techniques in Plant Disease Epidemiology. J. Kranz and J. Rotem, eds. Springer-Verlag, New York.

23. Newton, A. C., and Hackett, C. A. 1994. Subjective components of mildew assessment on spring barley. Eur. J. Plant Pathol. 100:395412.

24. Nita, M., Ellis, M. A., and Madden, L. V. 2003. Reliability and accuracy of visual estimation of
Phomopsis leaf blight of strawberry. Phytopathology 93:995-1005.

25. Nutter, F. W., Jr. 1989. Disease.Pro: A computer program for evaluating and improving a persons ability to assess disease proportion Phytopathology 79:1135.

26. Nutter, F. W., Jr., and Esker, P. D. 2006. The role of psychophysics in phytopathology. Eur J. Plant Pathol. 114:199-213.

27. Nutter, F. W., Jr., Esker, P. D., and Coelho Netto, R. A. 2006. Disease assessment concepts in Plant Pathology. Eur. J. Plant Pathol. 115:95-103.

28. Nutter, F. W., Jr., Gleason, M. L., Jenco, J. H., and Christians, N. C. 1993. Assessing the accuracy, intra-rater repeatability, and inter-rater reliability of disease assessment system. Phytopathology 83:806-812.

29. Nutter, F. W., Jr., and Schultz, P. M. 1995 Improving the accuracy and precision of disease assessment: Selection of methods and use of computer-aided training programs. Can. J. Plant Pathol. 17:174-178.

30. Parker, S. R., Whelan, M. J., and Royle, D. J. 1995. Reliable measurement of disease severity. Asp. App. Biol. 43:205-214.

31. Redman, C. E., King, E. P., and Brown, J. F., Jr. 1969. Elanco Conversion Tables for BarrattHorsfall Rating Numbers. Eli Lilly and Co. Research Labs., Indianapolis, IN.

32. Schubert, T. S., Gottwald, T. R., Rizvi, S. A., Graham, J. H., Sun, X., and Dixon, W. N. 2001. Meeting the challenge of eradicating citrus canker in Florida - again. Plant Dis. 85:340-356.

33. Sherwood, R. T., Berg, C. C., Hoover, M. R., and Zeiders, K. E. 1983. Illusions in visual assessment of Staganospora leaf spot of orchardgrass. Phytopathology 73:173-177.

34. Stevens, S. S. 1961. To honor Fechner and repeal his law. Science 133:80-86. 